IZA DP No. 7293

Hypergamy, Cross-boundary Marriages, and Family Behavior

Yoram Weiss

Junjian Yi

Junsen Zhang

March 2013 


\title{
Hypergamy, Cross-Boundary Marriages, and Family Behavior
}

\author{
Yoram Weiss \\ Tel Aviv University \\ and IZA \\ Junjian Yi \\ University of Chicago \\ Junsen Zhang \\ Chinese University of Hong Kong \\ and IZA \\ Discussion Paper No. 7293 \\ March 2013 \\ IZA \\ P.O. Box 7240 \\ 53072 Bonn \\ Germany \\ Phone: +49-228-3894-0 \\ Fax: +49-228-3894-180 \\ E-mail: iza@iza.org
}

Any opinions expressed here are those of the author(s) and not those of IZA. Research published in this series may include views on policy, but the institute itself takes no institutional policy positions. The IZA research network is committed to the IZA Guiding Principles of Research Integrity.

The Institute for the Study of Labor (IZA) in Bonn is a local and virtual international research center and a place of communication between science, politics and business. IZA is an independent nonprofit organization supported by Deutsche Post Foundation. The center is associated with the University of Bonn and offers a stimulating research environment through its international network, workshops and conferences, data service, project support, research visits and doctoral program. IZA engages in (i) original and internationally competitive research in all fields of labor economics, (ii) development of policy concepts, and (iii) dissemination of research results and concepts to the interested public.

IZA Discussion Papers often represent preliminary work and are circulated to encourage discussion. Citation of such a paper should account for its provisional character. A revised version may be available directly from the author. 


\begin{abstract}

\section{Hypergamy, Cross-Boundary Marriages, and Family Behavior ${ }^{*}$}

We study the rise in marriages between residents of HK and China following the handover of HK to China in 1997. Cross-boundary marriages accounted for almost half the marriages registered in HK in 2006. Because of large differences in male income between China and $\mathrm{HK}$, marriages of HK men with Mainland women outnumbered those of HK women with mainland men sevenfold. Following the handover, HK women had lower marriage, higher divorce and higher emigration rates. These outcomes are predicted by our matching model and contradict the hypothesis that cross-boundary marriages were driven by rising education of HK women.
\end{abstract}

JEL Classification: F22, J11, J12

Keywords: one-way permit, hypergamy, cross-boundary marriage, family behavior

Corresponding author:

Yoram Weiss

Faculty of Social Sciences

The Eitan Berglas School of Economics

Tel Aviv University

P.O.B. 39040

Ramat Aviv, Tel Aviv, 69978

Israel

E-mail: weiss@post.tau.ac.il

\footnotetext{
* The comments by Gary Becker and James Heckman are greatly appreciated. We thank Lena Edlund for the valuable comments in the early stage of this study. We also thank the seminar participants from the Labor Working Group Meeting at the University of Chicago, the University of Hong Kong, the University of Chicago-Renmin Symposium on Family and Labor Economics, and the 2013 Conference on Chinese Economy at CUHK.
} 


\section{Introduction}

Cross-national or cross-boundary marriages are an understudied research topic. Although economists have studied the open goods market (international trade), open financial market (international finance), and open labor market (international labor migration) for hundreds of years, the open marriage market is a new research topic in economics. However, cross-boundary marriages have increasingly become an important socioeconomic phenomenon. For example, in 2009, the number of international migrants under the family reunion scheme accounts for approximately $35 \%$ of the total number of international migrants around the world (International Migration Organization, 2010). Cross-boundary marriages have constituted up to 35\%-50\% of the newly registered marriages in Singapore and Hong Kong (HK) in recent years. Therefore, the subject of cross-boundary marriages deserves greater academic scrutiny.

The present paper both theoretically and empirically analyzes cross-boundary marriages. We first characterize the assignment profiles and utility shares in a simple twomarriage-market model with cross-boundary marriage costs. We assume that age is more important for women than for men in the marriage market when age is used as a proxy for beauty or fecundity. In contrast, income or wealth is assumed to be more important for men than for women because men usually carry the family financial responsibility. Under the assumption of gender asymmetry in evaluating individual attributes, women in poor regions are more attractive to men in rich regions than men in poor regions to women in rich regions. 1 This situation can result in more men from rich regions marrying women from poor regions than the opposite match, displaying a geographic manifestation of hypergamy: $\left.\right|^{2}$

With the decrease in cross-boundary marriage costs, more gender-asymmetric crossboundary marriages take place, which erode the relative position of women in rich regions not only in the marriage market but also within the household. As the well-being of women in rich regions has deteriorated after the increase in cross-boundary marriages, they may migrate to other richer regions. We call this a repercussion effect because it is a chain effect of the decrease in cross-boundary marriage costs.

We empirically test our theoretical predictions by investigating cross-boundary marriages between Mainland China and HK, which serves as a good setting for our study for several reasons: first, HK shares a similar social and cultural background with Mainland

\footnotetext{
${ }^{1}$ Our assumption on the gender asymmetry in evaluating individual attributes is consistent with the experimental evidences on the gender differences in mating selection (Fisman et al., 2006). They find that men respond more to women's physical attractiveness, whereas women prefer for men who grew up in affluent neighborhoods in a speed dating experiment.

${ }^{2}$ The term hypergamy is used specifically in reference to a tendency among human culture in which females pursue males of higher status than themselves. It often manifests itself as females being attracted to men who are comparatively older and wealthier. The hypergamy analyzed in this paper is the tendency of women in poor regions to marry men in rich regions. We thus call it as a geographic manifestation of hypergamy.
} 
China. The primary language used in HK is Cantonese, which is also the language used in Guangdong, the Mainland province neighboring HK. However, HK had been colonized by the United Kingdom for ninety-nine years, which resulted in a huge economic gap between Mainland China and HK $3^{3}$ Therefore, the similarity in social and cultural backgrounds and the huge economic gap provide great incentives for the Mainland women to marry up with HK men and lead HK women to avoid marrying down with Mainland men.

Second, the increase in cross-boundary marriages between residents of HK and Mainland China was triggered by clearly identifiable events: the handover of HK to Mainland China in 1997 and the discrete increases in the one-way permit (OWP) quotas. The handover greatly facilitated the interchange between the Mainland and HK residents. Furthermore, the cross-boundary marriage behavior is strictly governed by the OWP scheme, which requires all Mainland spouses or children of HK permanent residents to obtain an OWP document before moving to HK for family reunion 4 The daily quota of OWP was 75 in 1982, which increased to 105 in 1993, and then to 150 in 1995. Prior to 1996, the Mainland partners or children born in the Mainland normally had to wait eight to ten years to obtain an OWP. The waiting period was reduced to three to five years after 1995. Therefore, the handover and the discrete increases in the OWP quotas serve as good quasi-experiments that exogenously reduced cross-boundary marriage costs.

Third, the number of cross-boundary marriages is significant enough to change the fundamentals of the HK marriage market. Cross-boundary marriages accounted for almost half of all the marriages registered in HK in 2006 (Figure 1). Because of HK's superiority in public welfare, education, and medical systems, most Mainland partners and children of HK residents migrated to HK under the OWP scheme (Bacon-Shone et al., 2008). There were a total of 855,116 new arrivals under the OWP scheme from the Mainland in 1990-2008, accounting for $12.23 \%$ of the total population in 2008 and $69.85 \%$ of the population growth during the same period.

Finally, cross-boundary marriages are notable for inducing gender asymmetry: HK men marrying Mainland women outnumber that of the opposite match seven times during the period 1986-2006 (Figure 2). Therefore, the new arrivals under the OWP scheme have been dominated by females, leading to increasingly female-biased sex ratios in HK (Figure 3). This issue has drawn serious attention from the mass media, academic researchers, and the HK government (Bacon-Shone et al., 2008; HK Task Force on Population Policy, 2003) 5

\footnotetext{
${ }^{3}$ For example, when HK was handed over to Mainland China in 1997, the GPD per capita was US $\$ 27,055$ in HK, in contrast to the US\$770 in Mainland China and US\$1,800 in Guangdong (NBS, 1998).

${ }^{4}$ The OWP scheme is discussed in detail in the Background Section below.

${ }^{5}$ Another appealing feature of the HK experience is that labor migration from Mainland China is extremely restrictive. Labor migration was almost zero during the study period (Bacon-Shone et al., 2008).
} 
Using the quasi-natural experiments brought about by the handover of HK to China and the discrete increases in the OWP quotas, the present study constructs a difference-indifferences estimator to test the theoretical predictions. On the one hand, we use Taiwan residents as a comparison group, which is suitable for several reasons: HK, Taiwan, and Mainland China share the same Chinese cultural background. Both HK and Taiwan have traditionally sourced brides from the Mainland since the 1980s. Both regions experienced similar macroeconomic fluctuation such as the East Asian financial crisis during the 1990s. Furthermore, the immigration policy was rather stable in Taiwan during the study period. On the other hand, we use the HK 1990 and Taiwan 1991 census years as the pretreatment period and the HK 2001 and Taiwan 2000 census year as the post-treatment period.

Under this empirical strategy, we examine the reduced-form associations between regional changes in the residents' marital status, family structure, and intrahousehold bargaining power and the exogenous decrease in cross-boundary marriage costs. The empirical results show that the increases in the OWP quotas and the handover bolstered the males' relative position in the marriage market and diminished that of the females. Specifically, for women, the currently married and ever-married rates decreased, whereas the divorced rates increased. Furthermore, wives are less likely to be household heads. The results are opposite to that of men.

We further explore the richness of HK censuses and by-censuses (1991, 1996, 2001, and 2006) and check the gender differential changes in the marital status, family structure, intrahousehold bargaining, and labor market outcomes after the discrete changes in the OWP quotas and the handover. The gains focused on the HK censuses are two-fold. On the one hand, we are able to control the time trend with multiple censuses. On the other hand, there are detailed measures of the labor market outcomes in the HK censuses. The estimation results on the marital status, family structure, and intrahousehold bargaining are consistent with those when we use Taiwan residents as a comparison group. In addition, the increase in gender-asymmetric cross-boundary marriages induced by the discrete changes in the OWP quotas and the handover exerts an incentive effect on the HK women in the labor market relative to men. Women are more likely to participate in the labor force, be employed, and take a second job.

Finally, we use the US census 2000 and Canada census 2001 to examine the repercussion effect. Immigrants from Taiwan, Singapore, and South Korea are used as a comparison group, and the immigration years before 1997 as the pre-treatment period. We find that the emigration from HK has biased toward females since 1997.

The results are strongly consistent with our theoretical model. Furthermore, as predicted by the model, the changes are mainly concentrated on the lowly educated group. Therefore, the empirical results have established the decrease in cost of entry into HK as the main cause for the drastic increase in cross-boundary marriages between Mainland 
China and HK. Meanwhile, the results contradict the alternative hypothesis that the boom of higher female education has driven the rapid increase in cross-boundary marriages. Under this hypothesis, the change in marital status concentrates on the highly educated females, and the intrahousehold bargaining power tilts toward females with their higher educational attainment.

\subsection{Related Literature}

The present study explores a new topic on family behavior under the open marriage market in the literature. We mainly contribute to two strands of literature. The first strand of literature is related to marriage pattern. There is little economic research that explicitly studies marriage pattern such as hypergamy except Siow (1998) and Edlund (1999, 2005). Siow (1998) discusses the role of gender difference in fecundity in the spousal age gap. Edlund (1999) studies the marriage pattern of hypergamy in a society with son preference. With strong son preference, girls are expected to be systematically born in families with lower status. The fact may generate a general pattern that girls marry boys with higher status. Edlund (2005) considers the surplus of women in urban areas as a geographic manifestation of the general phenomenon of hypergamy in the marriage market. The marriage pattern of hypergamy has also been studied by sociologists who emphasize preferences. The economists, however, approach it by emphasizing endowments, competition, and market equilibrium. The present study both theoretically and empirically contributes to this strand of literature. On the one hand, we theoretically incorporate the gender-asymmetric attribute function into a two-marriage-market model and derive the gender-asymmetric cross-boundary marriages, leading to a geographic manifestation of hypergamy. We further analyze the utility shares under with gender-asymmetric crossboundary marriages. On the other hand, we systematically explore the consequences of the decrease in the cross-boundary marriage costs, and provide the empirical link of the cross-boundary marriage costs to marriage pattern and family behavior. The HK experience provides a precious identification opportunity because the decrease in the cross-boundary marriage costs was induced by the increase in the OWP quotas and the handover.

The other strand of literature refers to the relationship between the marriage-market conditions and family behavior. Because the gender-asymmetric cross-boundary marriages have directly changed the sex ratio in the HK marriage market, our study is closely related to the economic literature concerning the effects of sex ratio imbalance. Recently, a wave of new studies has examined the socioeconomic consequences of the changes in marriage-market conditions such as sex ratios (e.g., Angrist, 2002; Chang and Zhang, 2012; Chiappori, Fortin and Lacroix, 2002; Grossbard and Amuedo-Dorantes, 2008; Porter, 2007a, 2007b; Wei and Zhang, 2011a, 2011b; Lafortune, 2013). The emergence of the literature on sex ratios may be due to two major reasons. From the the- 
oretical perspective, the sex ratio is a direct measure of the marriage-market condition. The sex ratio directly affects the intrahousehold resource allocation and can thus be used to test the collective household behavior such as intrahousehold resource allocation and labor supply (Becker, 1973; Grossbard-Shechtman, 1993; Chiappori et al., 2002). From the policy perspective, the male-biased sex ratios, particularly in many Asian societies, have drawn increasing attention from government policy makers. Sen (1990) claims that "more than 100 million women are missing" because of the prevalent gender preference and gender selection in Asian societies.

Empirically, the recent literature on sex ratios has explored their variations induced by various sources. Grossbard and Amuedo-Dorantes (2008) and Porter (2007a, 2007b) utilize large cohort shifts in fertility or mortality rates that altered sex ratios to study the effects of sex ratio imbalance. Chiappori et al., (2002) use the regional variations in sex ratios. Wei and Zhang (2011a, 2001b) analyze the cross-region and cross-cohort variation in sex ratios induced by the one-child policy in Mainland China. Angrist (2002) uses the variation in sex ratios induced by immigration flow to the United States in the early part of the 20th century. Chang and Zhang (2012) explore a quasi-experiment that brought about the relaxation of the ban under which the soldiers were not allowed to marry when the Kuomintang Party retreated to Taiwan in the late 1940s. The relaxation of the ban induced exogenous variations in sex ratios in the marriage market. The literature has found far-reaching consequences of persistent sex ratio imbalance in the marriage and labor markets. The biased sex ratio can also affect intrahousehold and inter-household behavior.

The present study contributes to this strand of the literature by linking the decrease in cross-boundary marriage costs, gender-asymmetric cross-boundary marriages, sex ratio imbalance, and family behavior. The exogenous variation in sex ratios explored by Angrist (2002) originates from the interaction between endogamy within ethnic groups and the change in the number of migrations. The latter is mainly induced by the change in the American immigration laws. The exogenous variation in sex ratios in our study comes from the interaction between the hypergamy (where more women from poor regions are married to men in rich regions than the opposite match) and the decrease in crossboundary marriage costs. The latter is induced by the change in the exit policy in the Mainland side and the handover. Furthermore, Angrist (2002) studies the effects of the change in the ethnic group-specific sex ratios while implicitly keeping the aggregate sex ratio constant. On the contrary, because more than $97 \%$ of HK residents are married to either local residents or those from Mainland China, we analyze the effect of the change in the aggregate sex ratio. Finally, despite the burgeoning literature on sex ratios, most studies explore the consequences of male-biased sex ratios. In contrast, the present study examines the consequences of female-biased sex ratios. To complement the literature, studying the variations in sex ratios at the aggregate level and toward 
females can undoubtedly help us gain a full understanding of the relationship between marriage-market conditions and family behavior.

More importantly, echoing the view of Angrist (2002), the present study highlights the concept of virtual sex ratios in academic researches. Setting the argument in the HK context, both the sex ratio at birth and the sex ratio of the residents born in HK have been stable and balanced in the past three decades. Because of the interaction between hypergamy and the decrease in cross-boundary marriage costs, however, the sex ratio of the potential population in which HK men and women search for spouses is severely biased toward females. We call this sex ratio of the potential population in the marriage market the virtual sex ratio. The increase in the OWP quotas and the handover have decreased the cost of cross-boundary marriages between the residents of Mainland China and HK, and thus have decreased the virtual sex ratio with respect to the HK residents. Therefore, the present study casts doubt on the measurement of sex ratios by region and calls for caution in conceptually defining appropriate sex ratios.

The remainder of this paper is organized as follows. Section 2 presents the background of the OWP scheme, cross-boundary marriage, and gender imbalance in HK and discusses the spousal characteristics of cross-boundary marriages. Section 3 formulates the theoretical model and derives testable predictions. Section 4 introduces the data sets, and Section 5 specifies our empirical strategy. Section 6 presents our main empirical results, and Section 7 reports the repercussion effects. Section 8 concludes.

\section{Background}

\subsection{The One-way Permit, Cross-boundary Marriages, and Gender Imbalance in $\mathrm{HK}$}

Cross-boundary marriages have become an increasingly important element in marriages involving HK residents. Figure 1 shows the fraction of cross-boundary marriages in all marriages registered in HK from 1986 to 2006. ${ }^{6}$ The ratio shot up from 2\% in 1986 to $43 \%$ in $20067^{7}$ These marriages are also notable for the displayed gender asymmetry. The cases of HK men marrying Mainland women outnumber that of the opposite match six to seven times. Figure 2 shows the number of cross-boundary marriages registered in HK by residence of spouses from 1986 to 2006. Figure A1 in the web appendix shows the proportion of marriages registered in HK by residence of spouses from 1991 to 2006. The combination of Mainland brides and HK grooms has dominated the opposite match during the past two decades, although the combination of HK bride and Mainland groom has increased since 2000 .

\footnotetext{
${ }^{6}$ The total number of cross-boundary marriages registered in HK by gender during the period 1991 to 2006 is tabulated in Table A1 in the web appendix.

${ }^{7}$ Some cross-boundary marriages were registered in Mainland China. However, no aggregate statistics are available on the number of such marriages.
} 
The sharp increase in cross-boundary marriages between the residents of the Mainland and HK was triggered by a clearly identifiable event: the handover of HK to Mainland China in 1997. Furthermore, the cross-boundary marriage behavior in HK is strictly governed by the exit policies of the Mainland authority in which the OWP scheme is the single most important one. Compared with the lenient immigration policies for family reunion worldwide, extremely restrictive migration policies govern the residency of the Mainland Chinese in HK, even for the spouses and children of HK permanent residents.

The Mainland authority implements the OWP scheme to allow families with spouses and children residing in the Mainland to be reunited in $\mathrm{HK}$ while preventing a large volume of immigration to HK. The OWP is available to two groups of immigrants: children of permanent HK residents with Certificate of Entitlement, and spouses and other dependents. The OWP scheme stipulates that all Mainland spouses or children of HK permanent residents must obtain an OWP document to migrate to HK for reunion with their families. The daily quota of the OWP was 75 in 1982, went up to 105 in 1993, and then to 150 in 1995. Prior to 1993, the total number of new arrivals under the OWP scheme was less than 30,000 per year. In 1996, the number hit a record high of 61,179. Prior to 1993, a Mainland partner or a child born in Mainland China normally waited for eight to ten years to obtain an OWP; however, the waiting period has decreased to three to five years since 1995. The shorter waiting period greatly reduced both the material and psychological costs which in turn increased the number of cross-boundary marriages.

The new arrivals under the OWP scheme have been a major driver of the population growth in HK during the past two decades. Drawn by HK's superior public welfare, educational, and medical systems, most Mainland partners and children finally immigrated to HK through the OWP scheme. Therefore, these new arrivals constitute a lion's share of the population growth in HK (Figure A2 in the web appendix). In fact, there were 855,116 new arrivals under the OWP scheme during the 1990-2008 period, accounting for $12.23 \%$ of the total population in 2008 and $69.85 \%$ of the population growth during the same period. We also find two discrete jumps in the number of these arrivals coinciding with the two years when the OWP quotas were increased from 75 to 105 in 1993, and further to 150 in 1995. Figure A3 in the web appendix depicts the number of new arrivals under the OWP scheme by the type of relatives in HK. It shows that approximately half of the arrivals have spouses and the other half have parents in HK.

These new arrivals, induced by gender-asymmetric cross-boundary marriages, have severely biased the sex ratio in HK. Although the sex ratio of these new arrivals with parents in HK was almost balanced during the 1996-2006 period, the sex ratio of those new arrivals with spouses in HK was severely biased toward females (Figure A4 in the web appendix). Given the large scale of cross-boundary marriages and these new arrivals, the sex ratio of the HK population is severely biased toward females. Figure 3 shows that the sex ratio has experienced a monotonic decrease in the past decades. The sex 
ratio decreased more dramatically after the increase in the OWP quota in 1995 and the handover of HK in 19978 We thus conclude that the imbalance in the sex ratio in HK is attributable to the gender-asymmetric cross-boundary marriages between the residents of Mainland China and HK.

\subsection{Spousal Characteristics of Cross-Boundary Marriages}

We have discussed the trend of cross-boundary marriages between the residents of Mainland China and HK, the OWP scheme, and the relationship between the gender-asymmetric cross-boundary marriages and the sex ratio imbalance in the HK population. Questions remain as to who are involved in cross-boundary marriages and why. Mainland Chinese in cross-boundary marriages cannot migrate to HK immediately after the marriage; hence, we cannot access their information at the micro level. However, we can check the aggregate statistics about the spousal characteristics of cross-boundary marriages by residence type as reported by the HK Marriage and Records Office (CSD, 2007).

We check two types of spousal characteristics, that is, age and education. Table 1a summarizes the median age of marriage by sex and residence of spouse for all marriages registered in HK in 2006. Traditionally, Chinese husbands are, on average, two to three years older than their wives. This traditional protocol is confirmed by columns (1) and (4) with respect to the two marriage types of HK bride - HK groom and Mainland bride - Mainland groom. With regard to Mainland bride - HK groom, the husbands are, on average, nine years older than their wives (column (2)). In contrast, the husbands are, on average, younger than their wives with respect to HK bride - Mainland groom (column (3)).9 Table $1 \mathrm{~b}$ tabulates the distribution of the educational attainments of the grooms and brides who married in HK by residence of spouses in 2006. Cross-boundary marriages mainly involve individuals with low education; most of whom have not attained tertiary education 10

The aggregate statistics on the spousal characteristics in Tables 1a-b clearly display the geographic manifestation of hypergamy. Although the motivation for cross-boundary

\footnotetext{
${ }^{8}$ We can further check the robustness of the relationship between gender-asymmetric cross-boundary marriages and the biased sex ratio in the HK population. Figure A5 in the web appendix shows that the sex ratio at birth has been stable and balanced in the past decades. Furthermore, Figure A6 shows that the sex ratio of residents born in HK has also been stable and balanced, suggesting that the sex ratio imbalance is not due to the biased emigration of local HK residents. Section 7 shows that more females than males have emigrated to North America since 1997. However, the total number of emigrants is too small to change the sex ratio of the HK population.

${ }^{9}$ Figure A7 in the web appendix shows the proportion of marriages registered in HK by residence of spouse and difference in age. Among the four marriage types, Mainland bride - HK groom has the largest proportion of marriages with the brides younger than the grooms by at least five years. In contrast, HK bride - Mainland groom has the largest proportion of marriages with the brides older than the grooms by at least five years.

${ }^{10}$ Figure A8 shows the proportion of marriages registered in HK by residence of spouses and difference in educational attainment. Among the four marriage types, Mainland bride - HK groom has the largest proportion of marriages with better-educated grooms. On the contrary, HK bride - Mainland groom has the largest proportion of marriages with better-educated brides.
} 
marriage is multidimensional, the aggregate statistics show that, at least, age is an important factor. Given the huge population pool in the Mainland, HK males who are involved in cross-boundary marriages may want to find younger women. This fact leads to the marriage of young women in the poor region with old men in the rich region. These observations will be incorporated into our theoretical analysis when we model cross-boundary marriages and derive the testable predictions in the following section.

\section{The Model}

\subsection{The Autarky Marriage Market}

We begin with an autarky marriage market without migration, which sets up the benchmark for our theoretical analysis. We denote the marital relevant traits of the male and female by $m$ and $f$, respectively. These basic traits are assumed to be some known combinations of observed traits such as age and income. When individuals marry, their basic traits are combined to generate a single marital good according to the household production function

$$
h(m, f)=m f+m+f .
$$

The produced marital good can be divided between the partners so that the utility is transferable between partners. We further assume that the utility of the single equals his or her marital trait $m$ or $f$. The marital surplus is then given by $m f$, which is always positive, and therefore, everyone wants to marry if he or she finds a match and receives a positive share of the surplus. ${ }^{11}$

The assumed household production function is supermodular, indicating the complementarity of the male and female traits. This important feature can be rationalized by the increasing return in the household production function or household public goods (Lam, 1988; Weiss, 1997). Becker (1973) first noted that complementarity within the household induces a positive assortative match in the marriage market at large, implying that

$$
1-F(m)=r(1-G(f)),
$$

where $F(\cdot)$ and $G(\cdot)$ are the cumulative distribution functions of the traits for males and females, respectively, and $r$ is the ratio of women to men. We assume that $r<1 .{ }^{12}$

\footnotetext{
${ }^{11}$ For various reasons, some individuals may prefer to remain single even if a spouse is available. However, given our focus on potential cross-boundary marriages, our problem is substantially simplified if we assume that everyone wants to marry.

${ }^{12}$ Even though the sex ratio at birth is balanced, a shortage in women always occurs in the marriage market. The readers are referred to the discussions by Siow (1998) and Edlund (1999). One major reason is that women have a shorter reproductive window than men.
} 
For simplicity, we assume uniform distributions for the male and female traits

$$
\begin{aligned}
m & \sim[a, a+\delta], \\
f & \sim[b, b+\delta] .
\end{aligned}
$$

Given the uniform distributions, the assignment profiles are linear and given by

$$
\begin{aligned}
m & =r f+a+\delta-r(b+\delta) \equiv \phi(f) \text { for } f \geq b, \\
f & =\frac{m}{r}-\frac{a+\delta}{r}+(b+\delta) \equiv \psi(m) \text { for } m \geq m_{0}=a+\delta(1-r) .
\end{aligned}
$$

That is, all women are married and all men in the range $\left[a, m_{0}\right)$ are single. Figure 5 graphs the assignment profiles in the autarky marriage market case. The lowest match is by man $m_{0}$ and woman $b$, and the highest match is by man $a+\delta$ and woman $b+\delta$. We observe that $m_{0}$ increases with $\delta$ and decreases with $r$.

When a man $m$ is married to a woman $f$, we denote the shares of the man and woman as $u(m)$ and $v(f)$, respectively. Given that $h(m, f)=u(m)+v(f)$, the shares satisfy ${ }^{13}$

$$
\begin{aligned}
u(m) & =k^{m}+\int_{m_{0}}^{m} h_{m}(\phi(t), t) d t \\
v(f) & =k^{w}+\int_{b}^{f} h_{f}(s, \psi(s)) d s
\end{aligned}
$$

where

$$
\begin{aligned}
h_{m} & =f+1, \\
h_{f} & =m+1 .
\end{aligned}
$$

Hence, using Equations (3) and (4), we have

$$
\begin{aligned}
& u(m)=k^{m}+\int_{m_{0}}^{m}\left(1+\frac{s}{r}-\frac{a+\delta}{r}+(b+\delta)\right) d s \\
& v(f)=k^{w}+\int_{b}^{f}(1+r t+a+\delta-r(b+\delta)) d t .
\end{aligned}
$$

The constants $k^{m}$ and $k^{w}$ are determined by the condition that, because men outnumber women, the "last" married man should have no rent. Having assumed that singles consume their own "income," we set

$$
k^{m}=m_{0} .
$$

\footnotetext{
${ }^{13}$ For the derivation of the results, see Section 8.2.1 in Browning, Chiappori, and Weiss (2013).
} 
Hence, the woman who marries $m_{0}$ reaps all marital surplus of $m_{0} b$, and

$$
k^{w}=m_{0} b+b
$$

We call $m_{0} b$ as a "rent" enjoyed by all women because they are in the short side of the marriage market.

When more women are available and $r$ increases, fewer men are single and $m_{0}$ declines. We then have

$$
\begin{aligned}
\frac{d u(m)}{d r} & =\frac{\partial u(m)}{\partial m_{0}} \frac{\partial m_{0}}{\partial r}-\int_{m_{0}}^{m}\left(\frac{s-(a+\delta)}{r^{2}}\right) d s>0, \\
\frac{d v(f)}{d r} & =b \frac{\partial m_{0}}{\partial r}+\int_{b}^{f}(t-(b+\delta)) d t<0,
\end{aligned}
$$

where $\frac{\partial u(m)}{\partial m_{0}}=-b$, and $\frac{\partial m_{0}}{\partial r}=-\delta$. An increase in $r$ reduces the utility of all women and increases the utility of all married men. Conceptually, two effects arise on the male's share. The first term measures the "extensive margin" effect because the proportion of single men in the marriage market decreases with the increase in the share of women. The second term measures the "intensive margin" effect because the rise in the sex ratio directly changes the male's share in the marital output, which is a standard prediction in family economics 14

\subsection{The Gender-asymmetric Attribute Functions}

Before going directly to the analysis of cross-boundary marriages, we first define carefully the individual's attribute function. To fix the ideas, we define male $i$ and female $j^{\prime} s$ attributes $m$ and $f$ such that

$$
\begin{aligned}
m_{i} & =\alpha_{M} a e_{i}+\beta_{M} Y_{i}+\varepsilon_{i} \\
f_{j} & =\alpha_{F} a g e_{j}+\beta_{F} Y_{j}+\varepsilon_{j}
\end{aligned}
$$

where $Y$ measures wealth and $\varepsilon$ is a random shock to a person's pre-marital endowment. This simple formula imposes the same order in the two regions. Therefore, we can unambiguously rank men and women by their attributes, and we also have positive sorting on this scale. The coefficients $\alpha$ and $\beta$ can be different between any two regions such as Mainland China and HK. Imposing similar coefficients in the two regions not only makes much sense but also simplifies the task at hand. More importantly, $\alpha$ may have opposite signs for men and women, and wealth may be more important for men than for women. For example, $\alpha_{M}$ may be positive because men gain experience when they age, whereas $\alpha_{F}$ may be negative because beauty and fecundity decreases with age after a

\footnotetext{
${ }^{14}$ Becker (1991) and Browning et al. (2013).
} 
certain threshold.

The gender-asymmetry in the attribute function does not reflect the gender difference in preferences. Instead, it reflects the gender differences in wealth and age in the production of total marital outputs (Equation (1)). Because men usually take the family financial responsibility, the wealth is more important for men in producing marital outputs. In contrast, because women give birth to the children and the reproductive window is shorter for women, age is more important for them ${ }^{15}$ The specification of the genderasymmetric attribute function is consistent with our observed pattern of the spousal characteristics of cross-boundary marriages discussed in the previous section. Table 1a shows that age is an important factor for HK men to find Mainland women. Among the four marriage types, Figure A7 in the web appendix shows that Mainland bride - HK groom has the largest proportion of marriages with younger brides. In terms of education, Figure A8 shows that Mainland bride - HK groom has the largest proportion of marriages with better-educated grooms.

Individuals from different regions may have different marital endowments, $m_{i}$ and $f_{j}$. Men from poor regions, say, the Mainland, will be at the bottom of the male distribution (both HK and Mainland men), because they have low $Y$. This is not necessarily true for Mainland women because wealth is less important for women than men. If the cost of cross-boundary marriages is not sufficiently high, there exists a demand for Mainland brides in HK, in particular, for the young brides. In contrast, the demand for Mainland grooms is lower than that for the brides, resulting in a geographic manifestation of hypergamy. Therefore, the observed hypergamy in cross-boundary marriages can originate from the gender-asymmetric attribute functions and the very different distribution of the attributes between the two regions. This intuition is rigorously verified in the section below, in which hypergamy is an equilibrium outcome with cross-boundary marriages.

\subsection{Cross-boundary Marriages and Hypergamy}

We now consider cross-boundary marriages between a rich region such as $\mathrm{HK}$ and a poor region such as Mainland China. We shall focus on the equilibrium outcomes in HK. Concerning HK, we require that the outcome following cross-boundary marriages is stable. We therefore apply the principle that the aggregate marital output in HK is maximized (Koopmans and Beckmann, 1957; Shapley and Shubik, 1972).

Based on the gender-asymmetric attribute function and the huge income gap between HK and Mainland China, we make the following assumptions to simplify our analysis: (1) $r^{h}=r^{m}=r<1 ;(2) a^{m}=b^{m}=0 ;(3) a^{h}>b^{h}>016$ and (4) the population of

\footnotetext{
${ }^{15}$ The economic implications of the gender difference in fecundity is explored in Siow (1998).

${ }^{16}$ We actually do not require the assumption that the quality of HK men is higher than that of the women. The crucial assumption we need is that the gap of the quality between HK and Mainland men is larger than the gap between HK and Mainland women. The assumption originates from the gender asymmetric attribute function (Equations (11)-(12)). Since we have normalized both $a^{m}$ and $b^{m}$ to be zero, $a^{h}$ is then assumed to be larger than $b^{h}$.
} 
men in HK is normalized to one and that of the women to $r$, and there are $\sigma$ men and $r \sigma$ women in Mainland China, where $\sigma>1$. The superscripts $h$ and $m$ denote the rich region (HK) and the poor region (Mainland China), respectively. We assume that $\delta$ is the same in both regions and for both genders. Therefore, all four distributions are linear shifts of each other.

The marital output of the couples can be reduced to a function of the husband's quality. Let us first consider the marital output of the original local couples starting from the top. The stability of local marriages requires positive assortative mating, implying that $f=\frac{m}{r}-\frac{a+\delta}{r}+(b+\delta)$ (Equation (4)). Then, we can eliminate $f$ and calculate the output of the local marriages involving both HK residents for each $m$ as

$$
\begin{aligned}
G_{l}(m) & =m+f+m f \\
& =m+(1+m)\left(\frac{m}{r}-\frac{a^{h}+\delta}{r}+\left(b^{h}+\delta\right)\right) .
\end{aligned}
$$

We can also construct the output of the cross-boundary marriage involving a HK man $m$ and a Mainland woman $\tilde{f}$. Importing a Mainland woman involves two costs that do not apply to the marriage with a local woman. First, as noted above, there is a cost of waiting. Second, there is a cost associated with the fact that Chinese women have the opportunity to marry in China. The total value of such marriage is $(\tilde{m}+\tilde{f}+\tilde{m} \tilde{f})$. Although the wife would receive only a portion of this total value, there might be a need to compensate the husband too. We thus assume here that moving a woman from Mainland China to HK entails an opportunity cost that is equal to the full value of her potential marriage in Mainland China. ${ }^{17}$ Thus, we can define the (net) output of a mixed marriage in $\mathrm{HK}$ as

$$
\begin{aligned}
G_{c}(m) & =\omega(m+\tilde{f})+(1-\omega)(m+m \tilde{f}+\tilde{f})-(\tilde{f}+\tilde{m}+\tilde{m} \tilde{f}) \\
& =m+(1-\omega) m \tilde{f}-\tilde{m}(1+\tilde{f}),
\end{aligned}
$$

where $\tilde{m}$ and $\tilde{f}$ denote the Mainland man and woman respectively, and $\omega$ the waiting time. The total time after marriage is normalized to one.

We start from the top and use the positive assortative matching in HK to write $\tilde{f}$ as a function of $m$

$$
\begin{aligned}
r \sigma\left(\frac{\delta-\tilde{f})}{\delta}\right) & =\frac{a^{h}+\delta-m}{\delta}, \\
\tilde{f} & =\delta+\frac{m-a^{h}-\delta}{r \sigma} .
\end{aligned}
$$

\footnotetext{
${ }^{17}$ Analogous to the trade in goods, $(\tilde{m}+\tilde{f}+\tilde{m} \tilde{f})$ can be thought of as the cost of production and $\omega m \tilde{f}$ as the cost of transportation.
} 
We also use the assignment in Mainland China to eliminate $\tilde{m}$. We have $\tilde{m}=r \tilde{f}+\delta(1-r)$ (Equation (3)). Hence

$$
\begin{aligned}
G_{c}(m)= & m+(1-\omega) m\left(\delta+\frac{m-a^{h}-\delta}{r \sigma}\right) \\
& -\left(r\left(\delta+\frac{m-a^{h}-\delta}{r \sigma}\right)+\delta(1-r)\right)\left(1+\left(\delta+\frac{m-a^{h}-\delta}{r \sigma}\right)\right) .
\end{aligned}
$$

We conjecture an equilibrium in which there exists $m_{2}, m^{*}, \bar{m}$, and $m_{1}$, with $a^{h}+\delta>$ $m_{2}>m^{*}>\bar{m}>m_{1} \geq a^{h}$. The values of $m_{2}, m^{*}, \bar{m}$, and $m_{1}$ are cutoff points defined as follows. For men $m \in\left(m_{2}, a^{h}+\delta\right]$, marriages are local marriages with the original spouses as in the autarchy marriage market case; for $m \in\left(m^{*}, m_{2}\right]$ and $m \in\left(m_{1}, \bar{m}\right]$, all couples are new marriages with Mainland women; for $m \in\left(\bar{m}, m^{*}\right]$, men engage in local marriages with local women who are released by the men in the range $\left(m^{*}, m_{2}\right]$; the remaining men $m \in\left[a^{h}, m_{1}\right]$ are single.

This structure is quite intuitive because marrying a Mainland woman is costly to HK men. Top range local men $m \in\left(m_{2}, a^{h}+\delta\right]$ already have "good" wives and are unwilling to pay the cost of importing Mainland spouses. Men in the middle level $\left(m^{*}, m_{2}\right]$ could "profit" from the replacement of their original spouses with imported women if the cost is low and the Mainland spouses are "good" enough. Local men in the range $\left(\bar{m}, m^{*}\right]$ cannot afford Mainland women and, instead, marry replaced local women who are cheaper if available. For men in the range $\left(m_{1}, \bar{m}\right]$, they may marry imported Mainland women because, compared with the men in the range of $\left(\bar{m}, a^{h}+\delta\right]$, they do not have the choice to marry local women. They would remain single if they do not marry Mainland women. Finally, men at the bottom range $\left[a^{h}, m_{1}\right]$ remain single because no local woman is available, and they cannot afford the cross-boundary marriage costs.

We discuss the output of the marriages for men in each range and analytically pin down the optimal $m_{2}, m^{*}, \bar{m}$, and $m_{1}$. Men in the top range $\left(m_{2}, a^{h}+\delta\right]$ marry local women as in the autarky marriage market case. The marital output is defined in Equation (13). Men $m$ in the range $\left(m^{*}, m_{2}\right]$ marry Mainland women, and the marital output is

$$
\begin{aligned}
G_{c 1}\left(m ; m_{2}\right)= & m+(1-\omega) m\left(\delta+\frac{m-m_{2}}{r \sigma}\right) \\
& -\left(r\left(\delta+\frac{m-m_{2}}{r \sigma}\right)+\delta(1-r)\right)\left(1+\left(\delta+\frac{m-m_{2}}{r \sigma}\right)\right) .
\end{aligned}
$$

Positive assortative matching implies that a man $m$ in the range $\left[\bar{m}, m^{*}\right)$ receives the replaced local wife of the man $m_{2}-m^{*}+m$. Thus, we have the following identity

$$
m^{*}-\bar{m}=m_{2}-m^{*}
$$

The marital output for a man $m \in\left[\bar{m}, m^{*}\right)$ who marries the replaced local wife of $m_{2}-$ 
$m^{*}+m$ is

$$
G_{r}\left(m ; m_{2}, m^{*}\right)=m+(1+m)\left(\frac{m_{2}-m^{*}+m}{r}-\frac{a^{h}+\delta}{r}+\left(b^{h}+\delta\right)\right) .
$$

We note that

$$
G_{r}\left(m ; m_{2}, m^{*}\right)=G_{l}(m)+(1+m) \frac{m_{2}-m^{*}}{r},
$$

implying that $G_{r}\left(m ; \bar{m}, m^{*}\right) \geq G_{l}(m)$. Thus, the entry of foreign women allows some local men to obtain better wives than they would otherwise have. The men in the range $\left(m_{1}, \bar{m}\right]$ also marry Mainland women, and the marital output is

$$
\begin{aligned}
G_{c 2}\left(m ; m_{2}, m^{*}, \bar{m}\right)= & m+(1-\omega) m\left(\tilde{f}_{1}+\frac{m-\bar{m}}{r \sigma}\right) \\
& -\left(r\left(\tilde{f}_{1}+\frac{m-\bar{m}}{r \sigma}\right)+\delta(1-r)\right)\left(1+\left(\tilde{f}_{1}+\frac{m-\bar{m}}{r \sigma}\right)\right),
\end{aligned}
$$

where $\tilde{f}_{1}=\delta+\frac{m^{*}-m_{2}}{r \sigma}$. Finally, for men in the range $\left[a^{h}, m_{1}\right]$, they remain single.

Using the identity $m^{*}-\bar{m}=m_{2}-m^{*}$ to substitute out $m^{*}$, the aggregate marital output is then given by

$$
\begin{aligned}
S= & \int_{a^{h}}^{m_{1}} d m+\int_{m_{1}}^{\bar{m}} G_{c 2}\left(m ; m_{2}, \bar{m}\right) d m+\int_{\bar{m}}^{\frac{m_{2}-\bar{m}}{2}} G_{r}\left(m ; m_{2}, \bar{m}\right) d m \\
& +\int_{\frac{m_{2}-\bar{m}}{2}}^{m_{2}} G_{c 1}\left(m ; m_{2}\right) d m+\int_{m_{2}}^{a^{h}+\delta} G_{l}(m) d m .
\end{aligned}
$$

Because every stable match has to maximize the aggregate marital output (Koopmans and Beckmann, 1957; Shapley and Shubik, 1972), we are able to pin down the optimal $m_{1}, \bar{m}$, and $m_{2}$ by maximizing $S$ in Equation (14). Since $m^{*}=\frac{m_{2}-\bar{m}}{2}$, we can fully characterize the assignment profiles with cross-boundary marriages.

We first consider an interior solution that maximizes the aggregate marital output with cross-boundary marriages where the optimal $m_{2}, m^{*}, \bar{m}, m_{1} \in\left(a^{h}, a^{h}+\delta\right)$. Figure 6 graphs the matching profile in the interior solution case. Compared with the autarky marriage market case (Figure 5), all women still get married, whereas some men remain single. However, some women in the low tail of the attribute distribution are "pushed down" and married to HK men of lower quality than their original spouses in the autarky marriage market case. As for men, more men get married than that in the autarky marriage market case. Finally, Figure 6 shows that $m_{0}$ who is the last married man in the autarky marriage market case is now married to a replaced HK woman of better quality than the original woman $\left(b^{h}\right)$.

Corner solutions are possible when we maximize the aggregate marital output (Equation (14)). Specifically, two corner solutions are possible. The first is a corner solution with cross-boundary marriages. When the waiting period is sufficiently short, HK 
men can cream the best Mainland women given the large population. In this case, $\bar{m}=m_{1}=a^{h}$ and $m^{*}-a^{h} \leq m_{2}-m^{*}$. Figure 7 graphs the matching profile in this case. All HK men get married, whereas some HK women remain single.

The second is a corner solution in which no cross-boundary marriage takes place. When the waiting time is sufficiently long such that $G_{c}\left(a^{h}+\delta\right) \leq 0$, no cross-boundary marriage happens. The two-marriage-market model degenerates to the autarky marriage market case. Hence, the second case is identical to the autarky marriage market. The matching profile is shown in Figure 5 as we discussed in the previous section.

We therefore have three cases in the two-marriage-market model: the corner solution with no cross-boundary marriages (hereafter, autarky marriage market), the interior solution with cross-boundary marriages (hereafter, interior solution), and the corner solution with cross-boundary marriage (hereafter, corner solution). We tabulate the assignment profiles in the three cases as follows.

Table: Assignment profiles in autarky marriage market, interior solution, and corner solution

\begin{tabular}{|c|c|c|c|}
\hline & Autarky & Interior solution & Corner solution \\
\hline Range of traits & \multicolumn{3}{|c|}{ HK men } \\
\hline$\left(m_{2}, a^{h}+\delta\right]$ & local women & original local women & original local women \\
\hline$\left(m^{*}, m_{2}\right]^{1}$ & local women & Mainland women & Mainland women \\
\hline$\left(m_{0}, m^{*}\right]$ & local women & replaced local women & \\
\hline$\left(\bar{m}, m_{0}\right]$ & single & replaced local women & \\
\hline$\left(m_{1}, \bar{m}\right]$ & single & Mainland women & \\
\hline$\left[a^{h}, m_{1}\right]$ & single & single & \\
\hline Range of traits & \multicolumn{3}{|c|}{ HK women } \\
\hline$\left(f\left(m_{2}\right), b^{h}+\delta\right]^{2}$ & local men & original local men & original local men \\
\hline$\left(f\left(m^{*}\right), f\left(m_{2}\right)\right]$ & local men & replaced down & replaced down or single \\
\hline$\left[b^{h}, f\left(m^{*}\right)\right]$ & local men & replaced down & \\
\hline
\end{tabular}

1: The values of $m^{*}$ and $m_{2}$ in the interior solution case differ from those in the corner solution case. In the corner solution case, $m^{*}=a^{h}$.

$2: f(\cdot)$ is the assignment function in the autarky marriage market case.

The comparative static analysis of the matching profile with respect to a modestly discrete decrease in the waiting time, therefore, is conducted by comparing the matching profiles in the autarky marriage market case with that in the interior solution case (Figure 5 versus Figure 6). When the waiting time decreases to a sufficiently low level, the matching profile may change to that in the corner solution case (Figure 7). We summarize our result in the following proposition on the relationship between the discrete decreases in the waiting time and the changes in the matching profile. 
Proposition 1 When the waiting time decreases to a modestly low level, gender-asymmetric cross-boundary marriages involving Mainland brides and HK grooms take place, leading to a geographic manifestation of hypergamy. Compared with the autarky marriage market, more HK men get married. Some HK women in the low tail of the distribution are replaced by Mainland women. These women have to marry HK men in the lower tail of the distribution than those in the autarky marriage. When the waiting time decreases to a sufficiently low level, more HK women in the low tail of the distribution are replaced by Mainland women, and some of them remain single.

Next, we discuss the utility shares after cross-boundary marriages. Compared with the autarky marriage market case, all women lose, whereas all married men gain. However, the gains or losses are different for persons located in different parts of the attribute distribution. For women in the top range $\left(f\left(m_{2}\right), b^{h}+\delta\right]$, they marry the same persons as in the autarky marriage market case. But they lose the "rent" in Equation (8) because women are no longer at the short side of the marriage market. The total welfare for the women in the low range $\left[b^{h}, f\left(m_{2}\right)\right]$ decreases more than that for the women in the top range. In addition to the rent, their total welfare is lost because they marry inferior men than their partners in the autarky marriage market case. In contrast, men in the top range $\left(m_{2}, a^{h}+\delta\right]$ reap the rent. For men in the range $\left(m_{0}, m_{2}\right]$, in addition to the rent, their welfare increases because they marry better women. Furthermore, the originally single men in the range $\left(m_{1}, m_{0}\right]$ get married. When the waiting time decreases to a sufficiently low level, we arrive at the corner solution case where all men gain because they all get married. Furthermore, some women in the bottom of the distribution become single. They lose the most among all the HK residents. We summarize the discussion in the following proposition.

Proposition 2 When the waiting time decreases to a modestly low level, all married HK women receive lower utility whereas all married HK men receive higher utility. Women in the lower tail of the distribution lose more than those in the higher tail, and married men in the low tail of the distribution gain more than those in the high tail. When the waiting time decreases to a sufficiently low level, all men get married, and all men gain. Women in the bottom of the distribution who become single lose the most.

It is noted that these results depend on several simplifications made in our theoretical model. (1) The HK and the Mainland marriage markets are competitive with no search friction. There is only one consumption good and the utility is transferable. (2) Positive assortative matching results only from the consumption of the household public good or the increasing returns in the household production function. (3) We ignore the potential labor market gain for the Mainland brides. (4) We focus on the cross-boundary marriages between HK men and Mainland women and ignore the marriages between HK women with Mainland men. 
The first two assumptions are used only for analytic simplification. The latter two are based on the socioeconomic realities in HK. First, the labor force participation rates of the Mainland brides was as low as $20 \%$ after their migration to HK (Bacon-Shone et al., 2008). Moreover, they have to wait for several years before migrating. Therefore, their gains from the labor market are very low. Second, as we discussed in the Background Section, The cases of HK men marrying to Mainland women outnumber the opposite match seven times during our study period. Therefore, we focus on the analysis of HK men marrying Mainland women. The analysis actually depends on parameters $a^{h}, b^{h}$, $\sigma$, and $\delta$. When the gap between $a^{h}$ and $b^{h}$ is sufficiently small and the waiting time is sufficiently short, a mixed equilibrium could exist with some HK women marrying Mainland men. Despite these simplifications, the model still helps us analytically pin down the basic matching pattern of cross-boundary marriages.

\subsection{Testable Implications}

The theoretical model yields testable predictions that enable us to examine empirically the demographic and economic consequences of the changes in the OWP quotas and the handover. Due to data limitations, we are not able to structurally estimate the model ${ }^{18}$ Therefore, the empirical analysis focuses on testing the predictions explicitly derived from the comparative static analysis in the theoretical model. We also examine some predictions implicitly derived from our theoretical analysis.

As we shall show, these predictions differentiate our theory from an alternative theory in accounting for the increase in the gender-asymmetric cross-boundary marriages. The major alternative factor that explains the rapid growth of cross-boundary marriages is the boom of higher female education. Women's educational attainments have experienced rapid growth in both the developed and developing countries (Chiappori, Iyigun, and Weiss, 2009; Pitt, Rosenzweig, and Hassan, 2012; Becker, Hubbard, and Murphy, 2012). If the labor market becomes more favorable to women, especially those with higher education, more women will pursue higher education. Thus, women should have more intrahousehold bargaining power because they have more outside options. If the change in social norms that regulate the intrahousehold resource allocation lags behind the boom, higher educated women may prefer being single to being married. Thus, men in rich regions may shift to poor regions to search for brides. These men still prefer marriage because the traditional intrahousehold bargaining still tilts toward them. Kawaguchi and Lee (2012) posit this theory and use it to explain the increase in the gender-asymmetric cross-boundary marriages in Japan, South Korea, Taiwan, and Singapore since the early 1990s. This is logical, and the rapid increase in higher female education has been one of the major socioeconomic changes in these regions during the past two decades.

\footnotetext{
${ }^{18}$ We use the HK census data to conduct our empirical analysis. Because the Mainland spouses of HK residents in the new marriages are unable to migrate to HK immediately, they are not enumerated in the census at the time of the new marriage.
} 
Corollary 1 The decrease in cross-boundary marriage costs, which is induced by the increase in the OWP quotas and the handover, increases males' relative position in the marriage market and correspondingly decrease that of the females. Specifically, relative to men, it decreases women's currently married and ever-married rates, and increases women's divorced and not remarried rate. Furthermore, the change in the marital status should focus on the group with low socioeconomic status (SES).

This first prediction is directly derived from Proposition 1. But we need to pay attention to the "replacement" process. Proposition 1 is a statement about static comparison. In real life, with the decrease in cross-boundary marriage costs, a replacement process may occur via either divorce-and-remarriage or new mixed marriages ${ }^{19}$ In contrast to Corollary 1, the change in the marital status should focus on the group with high SES by the boom hypothesis.

Corollary 1 deals with marriage market issues. We now turn to the second prediction which directly follows Proposition 2. This prediction deals with the division of resources within the marriage.

Corollary 2 The intrahousehold bargaining power tilts toward men with the decrease in cross-boundary marriage costs.

In contrast, the boom hypothesis predicts increases in the bargaining power on the women's side because they have more outside options with the increase in female educational attainments. Although Proposition 2 states that women with low SES lose the most, Corollary 2 does not state that these women lose more intrahousehold bargaining power than women with high SES because these women marry men of lower quality in the interior solution case than those in the autarky marriage market case. Thus, the superiority of their relatively higher SES over their husbands compared with that in the autarky marriage market case helps them gain some intrahousehold bargaining power. In contrast, women with high SES are married to the same men as in the autarky marriage market case.

Corollaries 1 and 2 are explicitly derived from the model. Implicitly, however, our model suggests additional testable predictions that differentiate our theory from the boom hypothesis. Although our model does not directly address HK residents' labor supply and household work, one may conjecture that the changes in relative position in the marriage

\footnotetext{
${ }^{19}$ In the short run, the replacement process may occur through divorce-and-remarriage. In the long run, some local intact marriages, which would happen, no longer occur and instead we have new mixed marriages. The replacement may be mainly "hypothetical." It happens through new mixed marriage instead of divorce and remarriage. According to our empirical analysis in Table 3, five years after the increase in the OWP quotas, the HK women's divorce rate increased by $0.7 \%$ and the rate of being married decreased by $2.2 \%$ in 2000 compared with their Taiwanese counterparts. At the same time, the number of new mixed marriages have increased by five to six times.
} 
market and the relative bargaining power within the household between men and women also influence their labor market outcomes ${ }^{20}$ From here, we derive our third corollary.

Corollary 3 The decrease in cross-boundary marriage costs changes the men and women's incentives in the labor market. For example, the female labor force participation rate increases relative to that of men. Furthermore, the incentive effects are larger for women with low SES than for women with high SES.

The boom hypothesis also predicts an increase in the female labor force participation rate, which is a cause but not a consequence of cross-boundary marriages under the hypothesis. However, Corollary 3 differs from the boom hypothesis in at least two aspects. First, the increase in the female labor force participation rate in the boom hypothesis is due to the improvement in the labor market in favor of women, especially those with higher education. Corollary 3 states that the female labor force participation rate increases even in the absence of the improvement in the labor market. Second, Corollary 3 concludes that the labor force participation rate increases more for women with low SES because they lose more utilities after cross-boundary marriages than women with high SES. The boom hypothesis makes the opposite prediction.

So far, we have focused on the two-marriage market case. We now consider HK as a "more" open marriage market in the sense that HK residents could marry partners living in more developed regions. In this case, we expect a repercussion effect of crossboundary marriages. As the well-being of local female residents has deteriorated after the increase in cross-boundary marriages, women would be more likely to leave HK for other developed regions such as Canada and the US. Therefore, we may observe a chain of geographic manifestation of hypergamy. From here we have our fourth corollary which is implicitly derived from the theoretical model.

Corollary 4 The decrease in the cost of and the increase in gender-asymmetric crossboundary marriages have a repercussion effect on the HK marriage market. The increase in cross-boundary marriages could bias emigration from HK toward more females to the US and Canada. The repercussion effect should be larger for women with lower SES than those with higher SES.

The repercussion effect can also be derived from the boom hypothesis. However, in contrast to Corollary 4, the boom hypothesis expects a larger effect on women with higher SES. These corollaries are empirically tested in following sections. We discuss their policy implications in the final section.

\footnotetext{
${ }^{20}$ Grossbard (1993, ch.6)
} 


\section{Data}

To examine empirically the consequences of the decrease in cross-boundary marriage costs in the marriage market, within the household, and in the labor market in HK (Corollaries 1-3) ${ }^{21}$ we draw on the comprehensive census data sets from HK and Taiwan. This section describes these census data sets and presents a simple graphic analysis.

\subsection{HK Censuses: 1991, 1996, 2001, and 2006}

We first derive our data from the 1991 and 2001 HK population censuses and the 1996 and 2006 by-censuses. HK conducts a population census once every ten years and a one-tenth by-census in the middle of the intercensal period. We draw on 5\% samples from the 1991 and 2001 censuses and 50\% samples from the 1996 and 2006 by-censuses. Thus, each of the four samples contains $5 \%$ of the HK population in the census or inter-census year. In forming these four samples, actions have been taken such that all residential quarters have an equal probability of selection by the HK Census and Statistics Department. The censuses contain rich information such as demographic characteristics, family structure, and labor-market behavior.

We restrict our sample to HK residents who were born in HK. Most of the immigrants in HK during the past two decades have been through cross-boundary marriages between the residents of Mainland China and HK. Cross-boundary marriages are endogenous outcomes; hence, including immigrants through cross-boundary marriages may generate a selected sample. Furthermore, the sample that includes these immigrants is truncated because some Mainland partners of HK residents have not migrated to HK at the census survey time.

Tables 2a-b report the descriptive statistics based on the four waves of HK censuses (or by-censuses) by gender and by census year. To test Corollary 1, we use three variables to measure marital status: currently married, ever-married, and currently divorced.

To test Corollary 2, we use a dummy variable of being a household head as a proxy for intrahousehold bargaining power. It is an appropriate proxy variable. As defined by the census manual, "the head of a household is the person acknowledged by members of the household to make major decisions affecting the household." We include only married couples who were born in $\mathrm{HK}$ in the analysis of the intrahousehold bargaining power. Because the by-census 2006 codes the household head differently from others, we drop this by-census in our analysis with respect to intrahousehold bargaining ${ }^{22}$

To examine the incentive effects of the decrease in cross-boundary marriage costs (Corollary 3), we construct four variables to measure the HK resident's labor market outcomes: labor force participation, employment status, wages, and whether the individ-

\footnotetext{
${ }^{21}$ The data sets used to test the repercussion effect (Corollary 4) are introduced in Section 7 below.

${ }^{22}$ Only one head is reported in each household in censuses 1991 and 2001 and by-census 1996, whereas multiple heads in a household can be reported in by-census 2006.
} 
ual holds a second job.

\subsection{Taiwan Censuses: 1990 and 2000}

In our empirical analysis, we use Taiwan residents as a comparison group. Therefore, we supplement the HK censuses with the Taiwan censuses. Similar to HK, Taiwan conducts a population census once every ten years. The two recent censuses were conducted in 1990 and 2000. However, Taiwan does not conduct a by-census in the middle of the intercensal period. Therefore, we only use the 1990 and 2000 Taiwan census data. Two points are notable when we use the Taiwan censuses. First, to ensure comparability between the treatment and the comparison group, we choose only one city in Taiwan, that is, Taipei. Second, we restrict our sample to local Taipei residents.

Table 2c reports the summary statistics based on the 1990 and 2000 Taiwan census data. Similar to the HK census, the Taiwan census contains the same three variables that measure marital status and the household head as a proxy variable for intrahousehold bargaining power. However, the Taiwan censuses do not contain information on the individual's labor market outcomes as in the HK census.

\subsection{Graphic Analysis}

Based on the summary statistics in Tables $2 a-b$, this section presents the descriptive time series of the marital status of HK residents by gender. Figures 4a-c show the proportion of persons aged 15-65 who are currently married, ever-married, and currently divorced by gender. Two clear patterns are observed from these figures. First, the currently married, ever-married, and divorced and not remarried trends in HK have exhibited a genderdivergent pattern in the past two decades. For example, for males, the currently married rate has experienced substantial increase across the four census years. On the contrary, for females, the currently married rate has decreased. It is important to note that the currently married rate for males surpassed that for females in the 2006 by-census (Figure 4a), although historically, the currently married rate for the females has been higher than that for males across almost all societies (Becker, 1991). Given that both the sex ratio at birth (Figure A1 in the web appendix) and the sex ratio of the residents born in HK (Figure A2) have been stable and balanced in the past decades, these gender-divergent trends in the marriage status across HK residents can be well explained by cross-boundary marriages. Second, these gender-divergent patterns have been increasingly evident since the 1996 census, coincidentally with the increases in the OWP quotas and the handover. For example, the currently married rate for males has sharply increased since the 1996 census (Figure 4a). 


\section{Empirical Framework}

Although the graphic analysis is suggestive, we further conduct formal econometric analysis to examine empirically the predictions. The formal econometric analyses involve cross-region, cross-time, cross-gender, and cross-educational variations in the differential treatments of the increase in the OWP quotas and the handover. With all the necessary controls, estimating the effects of the policy changes and the handover suggests a causal relationship between the decrease in cross-boundary marriage costs and demographic and economic outcomes in HK. The increase in the OWP quotas directly reduces the cost, and the handover could also affect it.

Specifically, our basic regression equation is a difference-in-differences (DD) estimator,

$$
Y_{i}=\alpha_{0}+\alpha_{1} H K_{i}+\alpha_{2} T_{i}+\alpha_{3} H K_{i} * T_{i}+X_{i} \alpha_{4}+\varepsilon_{i}
$$

where the dependent variable $Y$ measures individual $i^{\prime} s$ marital status and intrahousehold bargaining power. We use HK censuses 1991 and 2001 and Taiwan censuses 1990 and 2000 in estimating Equation (15). Taiwan residents serve as a comparison group. Therefore, the independent variable $H K$ is equal to one if the individual is a HK resident, whereas it is equal to zero if the individual is from Taiwan. We use $T$ to indicate the post-treatment period which is equal to one if the individual is included in HK census 2001 or Taiwan census 2000. If the individual is included in HK census 1991 or Taiwan census 1990, T is equal to zero. $X$ is a vector of variables that measure the individual's characteristics such as age, age squared, and schooling years. $\varepsilon$ is an error term. We estimate Equation 15) for the male and female subsamples separately.

The interaction term $H K * T$ is used as a proxy variable for the decrease in crossboundary marriages ( $\omega$ in the theoretical model), which was induced by the discrete increase in the OWP quotas and the handover. So the coefficient of primary interest is $a_{3}$. The estimated $\alpha_{1}$ and $\alpha_{2}$ pick up the regional and time period differences in the outcomes. Therefore, $\alpha_{3}$ measures the cross-regional and cross-time changes in the outcomes driven by changes in the gender-asymmetric cross-boundary marriages.

If we assume that, without the discrete changes in the OWP quotas and the handover, HK and Taiwan local residents share a same time trend of marriage and intrahousehold behavior, $\alpha_{3}$ has a causal interpretation. Furthermore, the estimate of $\alpha_{3}$ provides us direct tests of Corollaries 1 and 2. For example, to test Corollary 1, we use the indicator of being currently married as the dependent variable. Corollary 1 then predicts $\alpha_{3}$ is positive for males and negative for females.

We believe that the identification assumption is plausible in our study context, although it is admittedly strong. Taiwan residents serve as a good comparison group for

HK residents for several reasons. First, Taiwan, HK, and the Mainland share the same Chinese cultural background. Second, Mainland China has been the dominant region for 
both Taiwan and HK citizens to source brides. Third, Taiwan and HK experienced similar macroeconomic fluctuation during the 1990s, such as the 1997 East Asian financial crisis. Finally, the Taiwan government did not change its marriage immigration policies during the 1990s. ${ }^{23}$

The endogeneity in the implementation of policies in the quasi-experimental studies (Meyer, 1995) may be less of a concern in our study. As discussed in the Background Section, the OWP scheme is controlled and implemented by the Mainland authority. Therefore, the policy changes in the OWP should be plausibly exogenous to the social and economic factors in HK. The 1997 handover of HK to Mainland China had been stipulated in the Convention for the Extension of HK Territory in 1898 and was scheduled in the Sino-British Joint Declaration in 1984. Therefore, it is unlikely that there is an endogenous choice of the discrete changes in the OWP quotas and the handover.

Despite these factors that favor our identification strategy, we further explore the richness of the four waves of HK census and by-censuses (1991, 1996, 2001, and 2006), and estimate the following alternative regression equation:

$$
Y_{i}=\beta_{0}+\beta_{1} \text { female }_{i}+\beta_{2} T_{i}+\beta_{3} \text { female }_{i} * T_{i}+X_{i} \beta_{4}+\text { trend }+\nu_{i} .
$$

The dependent variable $Y$ measures the marital, intrahousehold, or labor market outcome of individual $i$. The independent variable female measures the individual's gender. It is equal to one if the individual is a female; otherwise, it is equal to zero. $T$ equals one if the census year is 2001 or 2006; otherwise, for individuals included in 1991 or 1996, it equals zero. $T$ equals one indicating the post-treatment period ${ }^{24} X$ is a vector containing the control variables. $\nu$ is the error term.

We are interested in the estimated coefficient $\beta_{3}$ in Equation (16). The estimated $\beta_{1}$ and $\beta_{2}$ pick up the gender and time period differences in the individual outcomes. The estimated $\beta_{3}$ thus measures the changes in the gender differences in the outcomes across the change in the OWP quotas and the handover. The basic idea behind the estimation of Equation (16) is to examine whether the cross-gender and cross-cohort changes in the marriage and labor market behavior are related to the cross-cohort changes in the genderasymmetric cross-boundary marriages, which were induced by the discrete increases in the OWP quotas and the handover. The estimate of $\beta_{3}$ thus provides us tests for Corollaries 1-3. For example, we can use a dependent variable of being employed to test Corollary

\footnotetext{
${ }^{23}$ The Taiwan government strengthened its immigration policies to discourage marriage immigration in 2004 (Kawaguchi and Lee, 2012).

${ }^{24}$ As discussed earlier, the increase in the OWP quotas and the handover of HK to China in 1997 serve as quasi-natural experiments in reducing the cost of cross-boundary marriages. We classify the census year 1996 as the pre-treatment period. Although the number of OWP quotas increased to 150 in 1995 , the local marriage market in 1996 was not affected by the 1995 policy relaxation as it would take some time to generate any visible effects. The HK residents may need some time to find Mainland Chinese spouses. Thus, the effect of cross-boundary marriages may lag for one or two years to take place.
} 
3. We expect the estimated $\beta_{3}$ to be positive.

Compared with Equation (15), the gains from estimating Equation (16) are threefold. First, we can control the time trend because we have two periods prior to the treatment. Controlling for time trend is valuable in the quasi-experimental studies using the DD estimator (Meyer, 1995). Second, we can estimate Equation (16) using the highly and lowly educated subsamples, respectively ${ }^{25}$ By doing so, as discussed in the theoretical section, we can empirically distinguish our theory from the boom hypothesis in explaining the major behavioral motivation for the increase in cross-boundary marriages. Third, in contrast to the Taiwan census, the HK census contains rich information on the individual's labor market outcomes. We then estimate Equation (16) using many labor market outcomes as dependent variables to test Corollary 3. Therefore, we can examine the precondition for the alternative boom hypothesis that the labor market favored females during the 1990s. Meanwhile, as discussed in the previous section, we can check the incentive effects of the gender-asymmetric cross-boundary marriages on the labor market behavior of the HK residents. The disadvantage of estimating Equation 16) is that we cannot estimate the treatment effects on HK males and females separately. We can only estimate the differential treatment effects across gender.

In summary, guided by the theoretical model, the objective of our empirical analysis is to examine systematically the general pattern of the changes in the marriage market, intrahousehold, and labor market behavior between the male and female HK residents, and to relate the change pattern to the decrease in cross-boundary marriage costs. The latter was induced by the increase in the number of the OWP quotas and the handover. Although strong identification assumptions are involved in estimating Equations (15) and (16), our empirical analysis provides us an opportunity to test the predictions from the general theoretical model and to distinguish our model from the alternative hypothesis in accounting for the increase in cross-boundary marriages.

\section{Empirical Results}

This section reports our main empirical results. Table 3 presents the DD estimates of Equation (15) using Taiwan residents as a comparison group. These estimates capture the regional changes in the outcomes after the discrete increases in the OWP quotas and the handover. The top panel shows that, compared with Taiwanese women, HK women's currently married and ever-married rates decreased by 2.2 and 1.8 percentage points respectively, whereas their currently divorced rate increased by 0.7 percentage points after the increases in the OWP quotas and the handover. All estimates are statistically significant at a high level of $5 \%$ after adjusting for the region and census year clustering (column (2)). The results for the men are opposite to those for the women (column (3)). These

\footnotetext{
${ }^{25} \mathrm{HK}$ has adopted the British education system, which is substantially different from that in Taiwan. Therefore, we do not make this distinction in estimating Equation (15).
} 
results are consistent with Corollary 1, suggesting that the decrease in cross-boundary marriage costs enhances the marriage rate for men whereas it reduces for women. We conclude that the increases in the OWP quotas and the handover decrease women's relative position in the marriage market. The results presented in Table 3 imply that more Mainland women than men marry HK residents because $97 \%$ of HK residents are married to either local residents or those from Mainland China. Therefore, hypergamy happens with the increase in the OWP quotas and the handover.

The HK women's intrahousehold bargaining power decreased compared with Taiwan women during the same period. The lower panel of Table 3 reports that the probability of being a household head decreased by 6.3 percentage points for the HK women after the discrete increases in the OWP quotas and the handover, suggesting a decrease in their intrahousehold bargaining power. The estimate is statistically significant at a high level of $1 \%$. For men, the estimation results are opposite to those fro women. These results are consistent with Corollary 2. At the same time, the result contradicts the boom hypothesis.

Although the Taiwan residents serve as a good comparison group for the HK residents, it is possible that the time trend is different between the two regions even without the increases in the OWP quotas and the handover. This may be due to potential unobservable factors. Thus, we focus on the gender differential change in the outcomes of the HK residents below by estimating Equation (16). The results are reported in Table 4.

The top panel presents the results on the marital status. Column (2) shows that the change in gender difference in the marital status is consistent with those reported in the top panel of Table 4 when we use Taiwan residents as a comparison group, confirming Corollary 1 again. Relative to men, the currently married and ever-married rates decreased by 7.7 and 6.0 percentage points respectively, whereas the currently divorced rate increased by 1.5 percentage points. The three estimates are statistically significant at $1 \%$. When the whole sample is divided into two subsamples by education levels, we find that women with educational attainments lower than the tertiary level are more likely to be affected by cross-boundary marriages. The magnitudes (in terms of absolute values) of the three estimates for the highly educated group are only one-third to one-half of those for the lowly educated group. Furthermore, the estimates of the currently married and ever-married rates are statistically significant. These results are consistent with Corollary 1.

The middle panel reports the results of the family structure. As predicted by Corollary 2, the HK women's relative bargaining power within the household decreased with crossboundary marriages. This result is consistent with that reported in Table 3. When we split the sample by education levels, we find an interesting result. Relative to men, the decrease in the intrahousehold bargaining power is significantly larger for the highly educated women than that for the lowly educated ones. 
The apparent puzzle can be rationalized by our theoretical model. Both the lowly and highly educated women lose intrahousehold bargaining power with the decrease in crossboundary marriage costs, because they are no longer at the short side of the marriage market. However, the lowly educated women lose less than the highly educated group. On the one hand, the lowly educated women are married down with the increase in cross-boundary marriages. Thus, their SES relative to the husbands increases which can partly offset the overall decrease in their intrahousehold bargaining power. On the other hand, the highly educated women are married to the same husbands after the increase in cross-boundary marriages. The loss of intrahousehold bargaining power thus is larger for them. These results are strongly consistent with Corollary 2, whereas they contradict the boom hypothesis discussed in the theoretical analysis.

Combining the results reported in both the top and middle panels, we conclude that the HK women with high SES lose their welfare only at the "intensive" margin because of the loss in the intrahousehold bargaining power ${ }^{26}$ However, the HK women with low SES lose their welfare not only at the "extensive" margin but also at the "intensive" margin. The former is due to the decrease in the probability of being married and the increase in the probability of being divorced, and the latter is due to the loss in the intrahousehold bargaining power. The previous discussion indicates that the welfare loss at the intensive margin is larger for women with high SES than that for women with low SES. However, the relative decrease in the welfare is larger for the latter group, as a whole, because being involuntarily unmarried or divorced causes a large loss in an individual's welfare as specified in our theoretical model.

We then examine the labor market outcomes. The estimates are reported in the lower panel of Table 4. The HK women are more likely to participate in the labor market, to be employed, and to take a second job than men after the discrete increase in the OWP quotas and the handover, and their monthly wage income was also higher (column (2)). All four estimates are statistically significant at $1 \%$. We conclude that the results show an incentive effect on the HK women's labor market behavior, as predicted by Corollary 3, rather than the HK labor market becoming more favorable toward the HK women. First, although the female labor force participation rate increased by 8.1 percentage points, the employment rate increased by only 1.3 percentage points relative to the men ${ }^{27}$ This result implies that 6.8 percentage points of HK women who participated in the labor market were unemployed. The labor market actually becomes worse toward women. Second, the increase in the female's income is mainly because they worked harder. The estimates show that, although the wage income increased by $0.5 \%$, an increase of 0.6 percentage points occurs in the number of the HK women who took a second job. If we

\footnotetext{
${ }^{26}$ Although the rate of being currently divorced increased for the highly educated women, Table 4 reports insignificant effects of the decrease in the cross-boundary marriage costs on the rates of being currently married and ever married.

${ }^{27}$ The employment rate here is based on the total population.
} 
assume that the wage income of the second job is $80 \%$ of that of the first job, then a 0.6 percentage points increase in taking a second job translates into a $0.48 \%$ increase in the income. Thus, the gender difference in wage income has little change after the increase in cross-boundary marriages.

We split the sample by educational attainment, and the results are reported in columns (3) and (4). We find an incentive effect on both highly and lowly educated HK women relative to men, but the effect is larger for the lowly educated group. This result is consistent with our theoretical model in which the welfare of all HK women is negatively affected by the decrease in cross-boundary marriage costs, and women belong to the low tail in the distribution suffer the most (Proposition 2). The result also justifies the assumption used in our theoretical model. The gain for Mainland brides from crossboundary marriages is not mainly from the labor market because of their very low labor force participation (Bacon-Shone et al., 2008). If the Mainland brides whose quality is relatively low actively participate in the labor market, the competition in the labor market would become fiercer for the lowly educated HK women, and correspondingly, their wage income would decrease. However, the wage income increases only marginally for this group. Furthermore, our results with the labor market outcomes clearly contradict the boom hypothesis because the latter assumes that the labor market favored the highly educated women.

To sum up, the empirical results on the marital status, family structure, intrahousehold bargaining, and labor market outcomes are highly consistent with our theoretical predictions (Corollaries 1-3). The discrete increases in the OWP quotas and the handover decreased the cost of cross-boundary marriages, and reduced HK women's relative position both in the marriage market and within the household. The disadvantaged position of the HK women exerts an incentive effect on their labor market behavior.

The decrease in cross-boundary marriage costs induced more gender-asymmetric crossboundary marriages, which is similar to a decrease in the virtual sex ratio. Thus, the effect of the increase in the OWP quotas and the handover is similar to that of an increase in the share of females in the total population in the autarky marriage market case (Equations (9) and (10)). This correspondence directly links our results to the literature in examining the demographic and socioeconomic consequences of sex ratio imbalance, such as Angrist (2002). However, our results differ from those of Angrist (2002) in some aspects. For example, he finds that the increase in sex ratios enhances the currently married rates for both males and females. He further finds that the effects on the females are consistently larger than those on males in both demographic and economic outcomes. Our results, as reported in Table 3, show contrasting effects on men and women. Furthermore, the magnitude of the effects (in terms of absolute values) on men and women appears to be very similar. These differences mainly originate from the fact that, whereas Angrist (2002) analyzes the change in the group-specific sex ratios by keeping the aggregate sex 
ratios constant, we focus on the economy-wide variations in the sex ratios.

\section{Repercussion Effects}

This section tests the repercussion effect of cross-boundary marriages as stated in Corollary 4. We use the 2001 Canada Census Integrated Public Use Microdata Series (IPUMS) file (2.5\% sample) and the 2000 US Census IPUMS file (5\% sample), and focus on the immigrants in these countries. Given the fact that approximately $80 \%$ of the HK emigrants moved to North America, the HK immigrants in the two censuses constitute a major sample of the HK emigrant population. We draw on two subsamples from the two censuses. The first subsample includes all those who have immigrated to the US or Canada since 1991. To ensure comparability of the treatment and the comparison groups in our estimation of the repercussion effect, we further restrict the first subsample to one that includes only immigrants who came from HK, Taiwan, Singapore, and South Korea, which gives us the second subsample. Given that these four economies are known as the "Asia's Four Little Tigers" in terms of their economic performance, we consider that the immigrants from Taiwan, Singapore, and South Korea constitute a sound comparison group with those from HK.

Based on the two subsamples, we focus on the estimation of the following equation:

$$
\text { Gender }_{i}=\gamma_{0}+\gamma_{1} T_{i}+\gamma_{2} H K_{i}+\gamma_{3} T_{i} * H K_{i}+X_{i} \gamma_{4}+U S_{i}+\varepsilon_{i}
$$

The above equation is similar to Equation (15). We use a dummy variable Gender as the dependent variable. It equals one if the immigrant is a female; otherwise, it equals zero. With regard to the independent variable $T$ that measures the treatment period, we consider 1991-1996 as the pre-treatment period and 1997 onward as the post-treatment period. We further consider the immigrants from HK as the treatment group $(H K=1)$ and the immigrants from other places as the comparison group $(H K=0) . X$ is a vector of variables that measure individual characteristics. Finally, given that we pool two census data sets, we include a dummy variable $U S$ that indicates the US census. $\varepsilon$ is the error term.

Corollary 4 predicts that $\gamma_{3}$ is positive, and the magnitude of $\gamma_{3}$ should be larger (in terms of absolute value) in the sample of lowly educated group. The results are reported in Table 5. Using all other immigrants in North America as a comparison group, column (1) of Panel A reports the change in the gender difference in immigrants from HK. HK women are more likely to migrate than men to North America after the increase in the OWP quotas and the handover. The estimate of $\gamma_{3}$ is both statistically and economically significant. Relative to the immigrants from other regions, the number of females from HK have increased by 6.8 per 100 immigrants since 1997.

In column (4) of Panel B, we restrict the comparison group to immigrants from Tai- 
wan, Singapore, and South Korea in North America. The results are very similar to those reported in column (1). Finally, the increase in the female immigrants from HK since 1997 is concentrated on the lowly educated group. Therefore, we conclude that the results reported in Table 5 show that cross-boundary marriages induced by the increase in the OWP quotas and the handover a greater number of lowly educated women to migrate to North America as compared with other groups. These results are strongly consistent with Corollary 4, and again contradict the boom hypothesis.

\section{Discussion and Conclusion}

We theoretically and empirically investigate cross-boundary marriages and their demographic and economic consequences. Because of the gender asymmetry in evaluating individual attributes in the marriage market, more women marry from poor regions to men in rich regions than the opposite match. We thus expect a geographic manifestation of hypergamy. When cross-boundary marriage costs decrease, more gender-asymmetric cross-boundary marriages take place. The relative position of women in rich regions deteriorates both in the marriage market and within the household. The disadvantaged position further exerts an incentive effect on their labor market behavior. Finally, there is a repercussion effect of the increase in cross-boundary marriages that drives more women than men in the rich regions to migrate to richer regions, displaying a chain of geographic manifestation of hypergamy. These theoretical predictions are confirmed by our empirical analysis on the cross-boundary marriage between Mainland China and HK.

Guided by the theoretical model, our empirical analysis establishes the interaction between the hypergamy and the cost reduction as the driving force for the drastic increase in gender-asymmetric cross-boundary marriages in HK. The empirical results contradict the alternative hypothesis based on the boom of higher female education. Our theory may also account for the increase in cross-boundary marriages in the other regions such as Taiwan, South Korea, and Singapore. Along with the revolution in communication technologies during the past decades, cross-boundary marriage costs may have decreased in these regions, which in turn increases the demand for cross-boundary marriages and further stimulates the service market for cross-boundary marriages. The flourishing of cross-boundary marriage brokers and the Internet dating systems further reduce the cost. As these effects reinforce each other, a drastic increase in the gender-asymmetric crossboundary marriages takes place. For females in the low tail of the distribution in these East Asian regions, the fiercer competition for grooms could lead to the boom in higher female education. Under this hypothesized logic, the boom in higher female education is the consequence rather than the cause of the increase in cross-boundary marriages. We analyze this hypothesis in another study. The decrease in cross-boundary marriage costs, however, is usually entangled with the change in other socioeconomic factors, positing an identification problem in empirical testing. The value of the HK experience is that 
cross-boundary marriages are strictly regulated by the exit policy in the Mainland side. The increases in the OWP quotas and the handover serve as quasi-experiments that exogenously reduce the cost compared with neighboring regions such as Taiwan.

Finally, the present study raises a normative issue. As demonstrated by our theoretical model and verified by the empirical results, the total welfare increases from the autarky marriage market case to the interior solution case with cross-boundary marriages because the optimal assignment profile in the autarky marriage case is still a possible choice in the latter case. However, the welfare of women in the rich regions decreases. Therefore, relaxing the marriage immigration policies is not Pareto-improving. Governments do face the equality versus efficiency trade-off if they implement and revise these policies. 


\section{References}

[1] Angrist, Joshua, 2002, How Do Sex Ratios Affect Marriage and Labor Markets? Evidence from America's Second Generation, Quarterly Journal of Economics 117(3), 997-1038.

[2] Bacon-Shone, John, Joanna K.C. Lam, and Paul S.F. Yip, 2008, The Past and Future of the One Way Permit Scheme in the Context of a Population Policy for Hong Kong, Bauhinia Foundation Research Centre.

[3] Becker, Gary S., 1973, A Theory of Marriage: Part I, Journal of Political Economy 81(4), 813-46.

[4] Becker, Gary S., 1991, A Treatise on the Family, Harvard University Press, Enlarged edition Cambridge, Mass.

[5] Becker, Gary S., Hubbard, W., and Murphy, K., 2010, The Market for College Graduates and the Worldwide Boom in Higher Education of Women, American Economic Review Pages and Proceedings, 100(2), 229-33.

[6] Browning, M., Chiappori, P. and Weiss, Y., 2013, Family Economics, Manuscript.

[7] Census and Statistics Department (CSD), 2007, Marriage and Divorce Trends in Hong Kong, 1981 to 2006, Hong Kong Government Printer.

[8] Chang, Simon, and Xiaobo Zhang, 2012, The Economic Consequences of Excess Men Evidence from a Natural Experiment in Taiwan, IFPRI Discussion Paper No. 01203,

[9] Chiappori, Pierre-Andre, Bernard Fortin, and Guy Lacroix, 2002, Marriage Market, Divorce Legislation and Household Labor Supply, Journal of Political Economy $110(1), 37-72$.

[10] Chiappori, P. A., Iyigun, M. and Weiss, Y., 2009. "Investment in schooling and the marriage market." American Economic Review, 99(5), 1689-713.

[11] Edlund, Lena, 1999, Son Preference, Sex Ratios, and Marriage Patterns, Journal of Political Economy 107(6), 1275-1304.

[12] Edlund, Lena, 2005, Sex and the City, Scandinavian Journal of Economics, 107(1), $25-44$.

[13] Fisman, R., S. Iyengar, E. Kamenica, and I. Simonson, 2006. Gender Differences in Mate Selection: Evidence from a Speed Dating Experiment. Quarterly Journal of Economics, 121(2), 673-97. 
[14] Grossbard, S., 1993, On the Economics of Marriage: A Theory of Marriage, Labor, and Divorce. Westview Press, Boulder, CO.

[15] Grossbard, S. and Amuedo-Dorantes, C., 2008, Cohort-level Sex Ratio Effects on Women's Labor Force Participation, Review of Economics of the Household, 5(2), 249-278.

[16] Hong Kong Task Force on Population Policy, 2003. Report of the Task Force on Population Policy, Hong Kong Government Printer.

[17] International Migration Organization, 2010, World Migration Report, McGill Press.

[18] Kawaguchi, D. and Lee, S., 2012, Brides for Sale: Cross-border Marriages and Female Immigration, University of Maryland Working Paper.

[19] Koopmans, T. and Beckmann, M., 1957, Assignment Problems and the Location of Economic Activities, Econometrica, 25(1), 53-76.

[20] Lafortune, Jeanne, 2013, Making Yourself Attractive: Pre-Marital Investments and the Returns to Education on the Marriage Market. American Economic Journal: Applied Economics, forthcoming.

[21] Lam, D. 1988, Marriage Markets and Assortative Mating with Household Public Goods: Theoretical Results and Empirical Implications, Journal of Human Resources, 23(4), 462-487.

[22] Meyer, B. D. 1995. "Natural and Quasi-Experiments in Economics." Journal of Business and Economic Statistics, 13(2), 151-61.

[23] National Bureau of Statistics (NBS), 1998, Chinese Statistics Yearbook, Beijing: China Statistic Press.

[24] Pitt, M., Rosenzweig, M., Hassan, M., 2012, Human Capital Investment and the Gender Division of Labor in a Brawn-Based Economy, American Economic Review, 102(7), 3531-60..

[25] Porter, Maria, 2007a, The Effect of Sex Ratio Imbalance in China on Marriage and Household Bargaining. University of Chicago Working Paper.

[26] Porter, Maria, 2007b, How Marriage Market Conditions in China Influence Intergenerational Transfers. University of Chicago Working Paper.

[27] Sen, A. 1990. "More than 100 million women are missing." New York Review of Books, 37:20, pp. 61-66. 
[28] Shapley, L. and Shubik, M., 1972, The Assignment Game I: The Core, International Journal of Game Theory, 1, 111-30.

[29] Siow, Aloysius, 1998, Differential Fecundity, Markets, and Gender Roles, Journal of Political Economy 106(2), 334-54.

[30] Wei, Shang-Jin, and Xiaobo Zhang, 2011a, The Competitive Saving Motive: Evidence from Rising Sex Ratios and Savings Rates in China, Journal of Political Economy, 119 (3): 511-564.

[31] Wei, Shang-Jin, and Xiaobo Zhang, 2011b, Sex Ratios, Entrepreneurship and Economic Growth in the People's Republic of China, NBER working paper 16800.

[32] Weiss, Yoram., 1997, The Formation and Dissolution of Families: Why Marry? Who Marries Whom? and What Happens upon Marriage and Divorce. In Rosenzweig, M. and Stark, O., (Eds) Handbook of Population and Family Economics. Volume 1A. Amsterdam; New York and Oxford: Elsevier Science, North-Holland. 


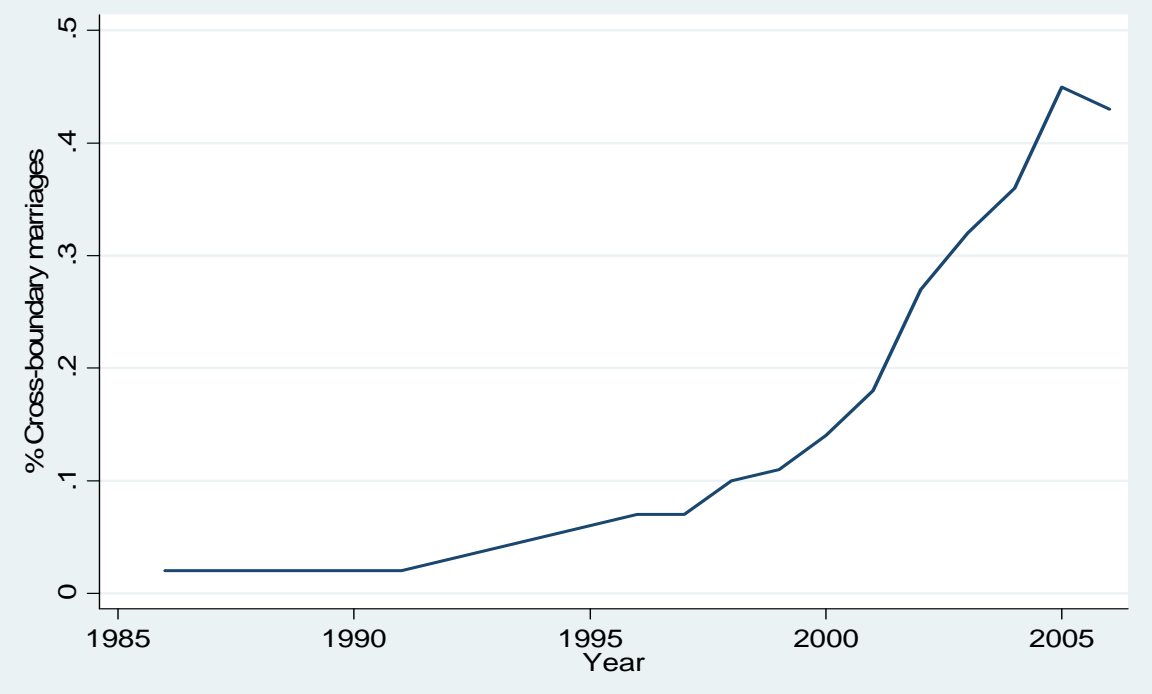

Figure 1. The fraction of cross-boundary marriages in all marriages registered in Hong Kong, 1986-2006

Data source: Census and Statistics Department, 2007, Marriage and Divorce Trends in Hong Kong, 1981 to 2006, Hong Kong: Census and Statistics Department Printing. 


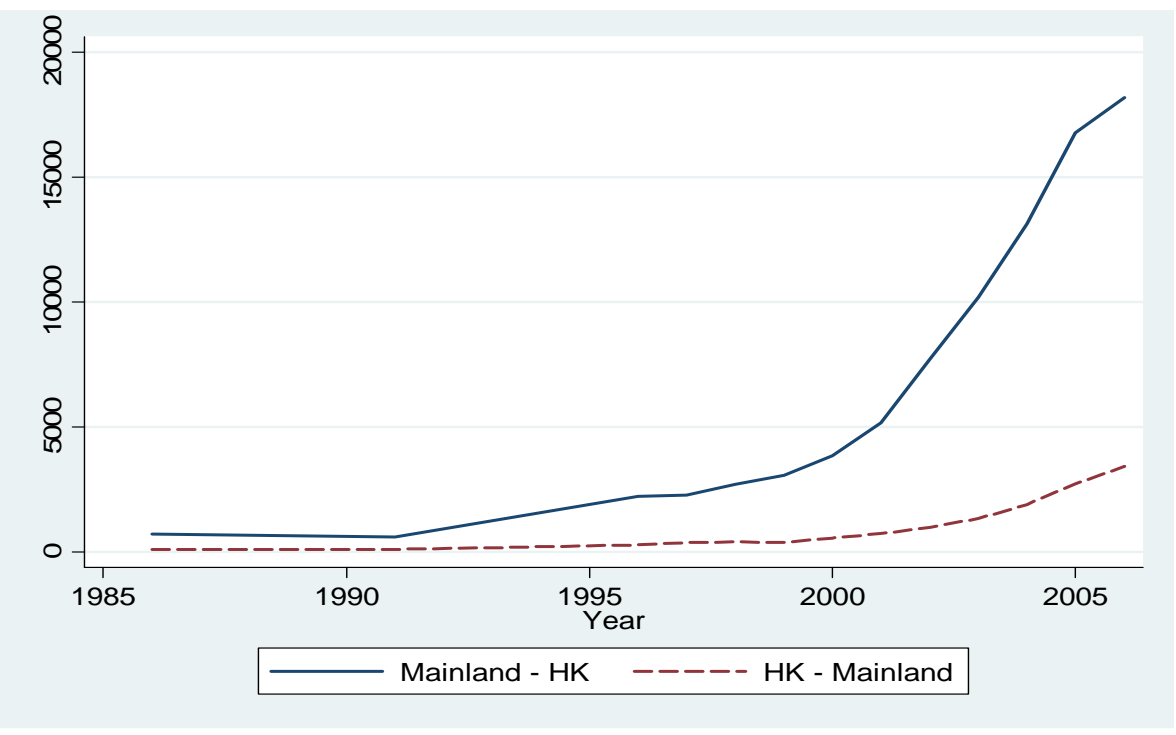

Figure 2. Number of cross-boundary marriages registered in Hong Kong by residence of spouse, 1986-2006

Data source: Census and Statistics Department, 2007, Marriage and Divorce Trends in Hong Kong, 1981 to 2006, Hong Kong: Census and Statistics Department Press.

Note: Mainland - HK: Mainland bride and Hong Kong groom; HK - Mainland: Hong Kong bride and Mainland groom. 


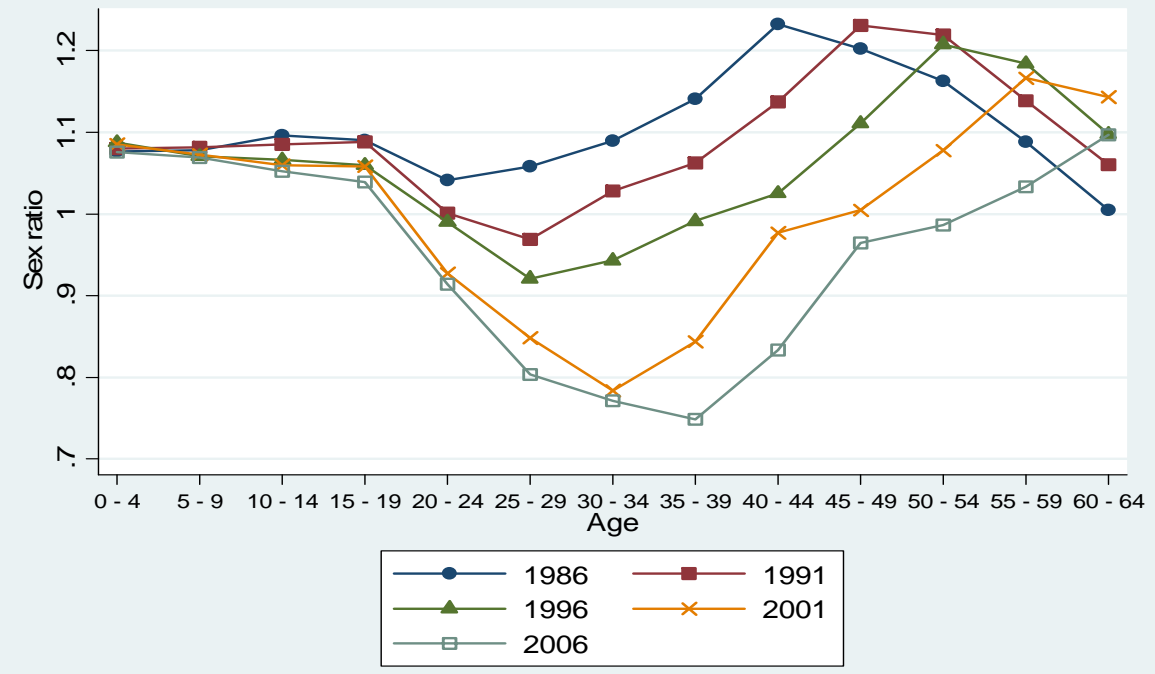

Figure 3. Sex ratios (males/females) by age group and by year in Hong Kong (whole population), 1986-2006

Data Sources: The 1991, 2001 Hong Kong censuses (5\% sample) and the 1986, 1996, and 2006 Hong Kong by-censuses (50\% sample) 


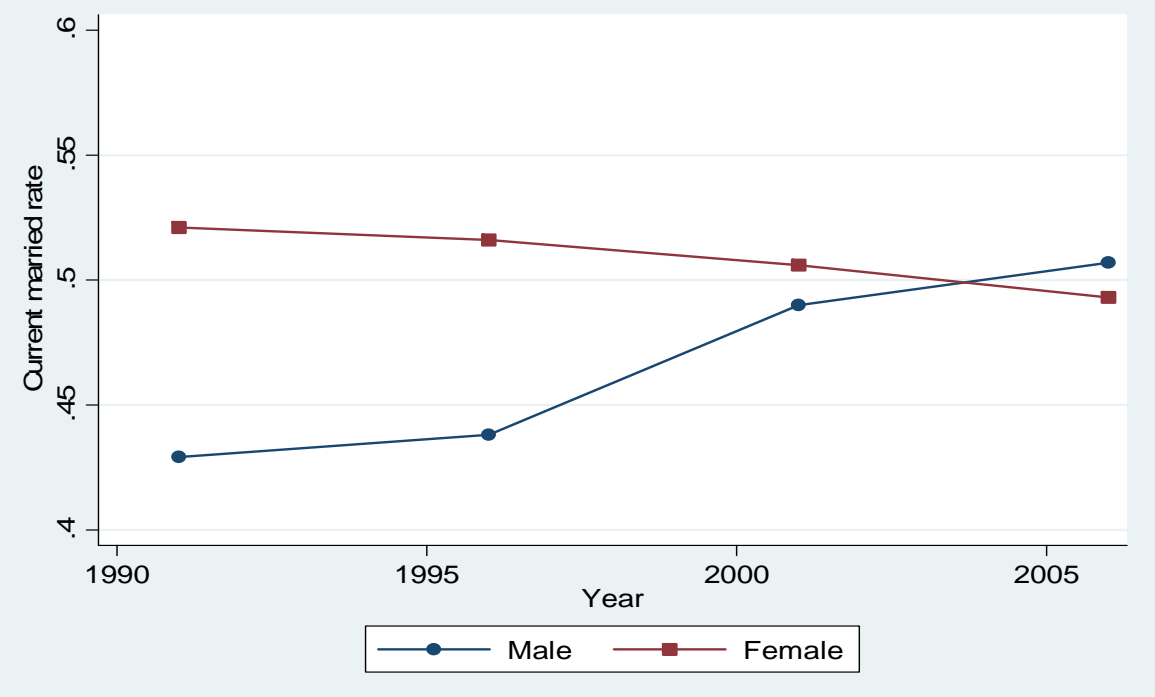

Figure 4a. The proportion of persons aged 15-65 who were born in Hong Kong and were currently married by year and by gender, 1991-2006

Data Sources: The 1991, 2001 Hong Kong censuses (5\% sample) and the 1996, and 2006 Hong Kong by-censuses ( $50 \%$ sample) 


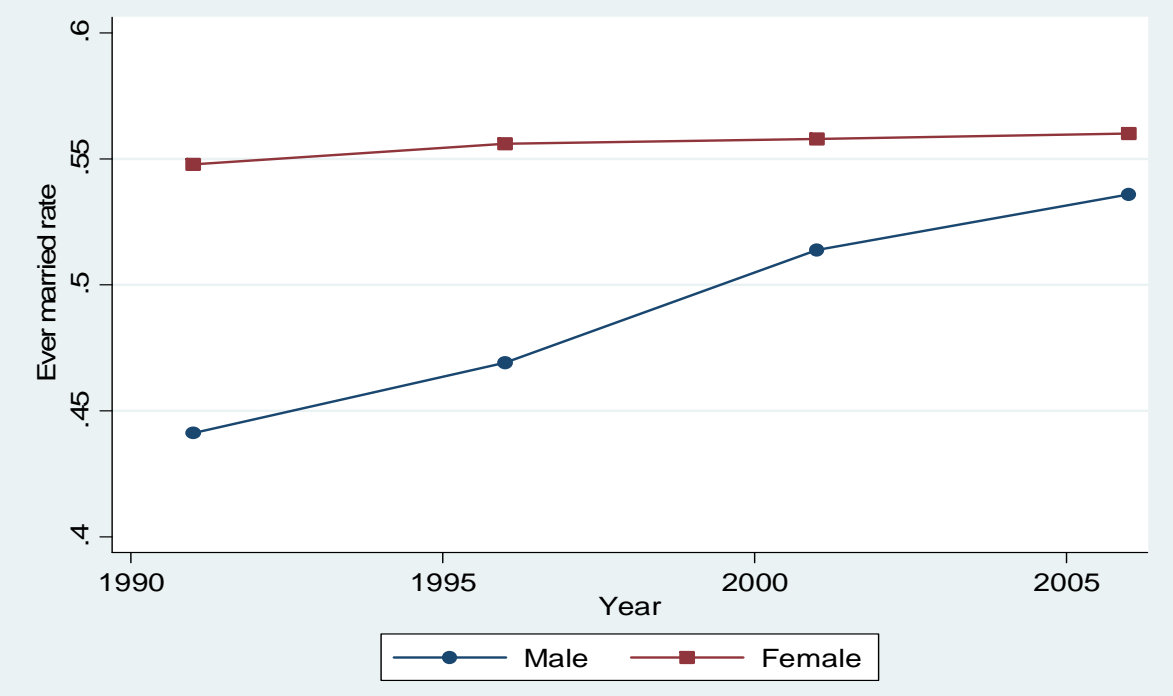

Figure 4b. The proportion of persons aged 15-65 who were born in Hong Kong and were ever married by year and by gender, 1991-2006

Data Sources: The 1991, 2001 Hong Kong censuses (5\% sample) and the 1996, and 2006 Hong Kong by-censuses (50\% sample) 


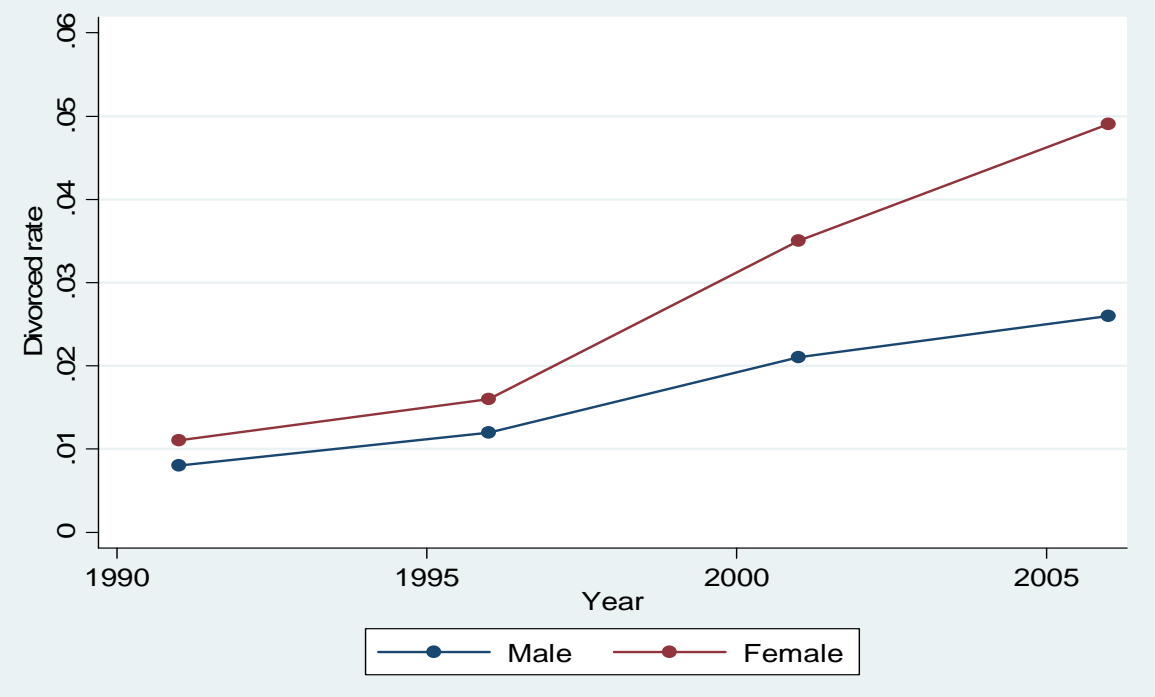

Figure 4c. The proportion of persons aged 15-65 who were born in Hong Kong and were currently divorced by year and by gender, 1991-2006

Data Sources: The 1991, 2001 Hong Kong censuses (5\% sample) and the 1996, and 2006 Hong Kong by-censuses ( $50 \%$ sample) 


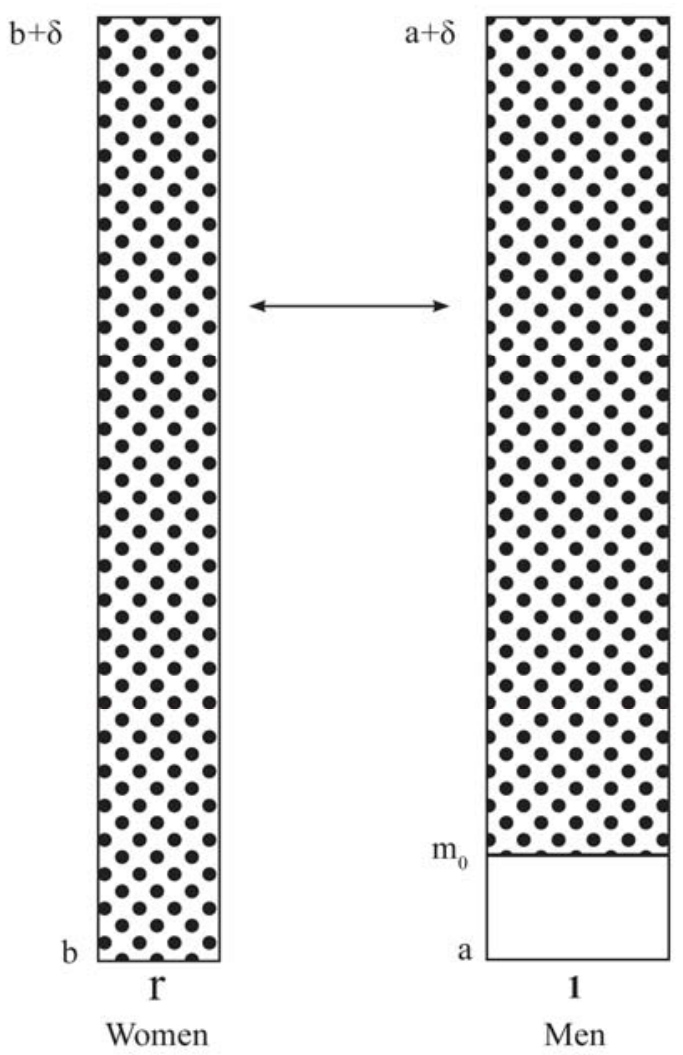

Figure 5. The assignment profiles in the autarky marriage market 


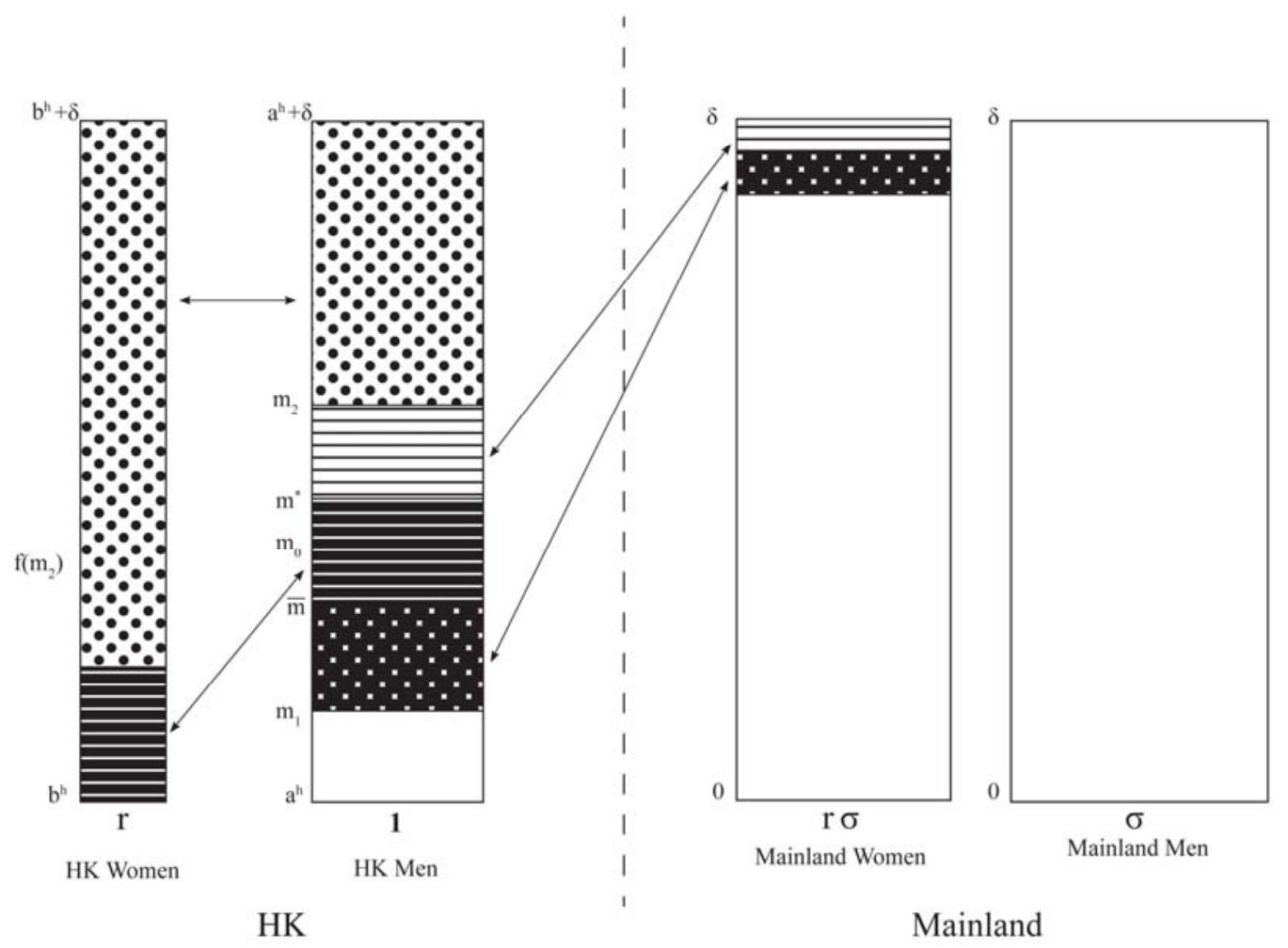

Figure 6. The assignment profiles in the interior solution with cross-boundary marriages 


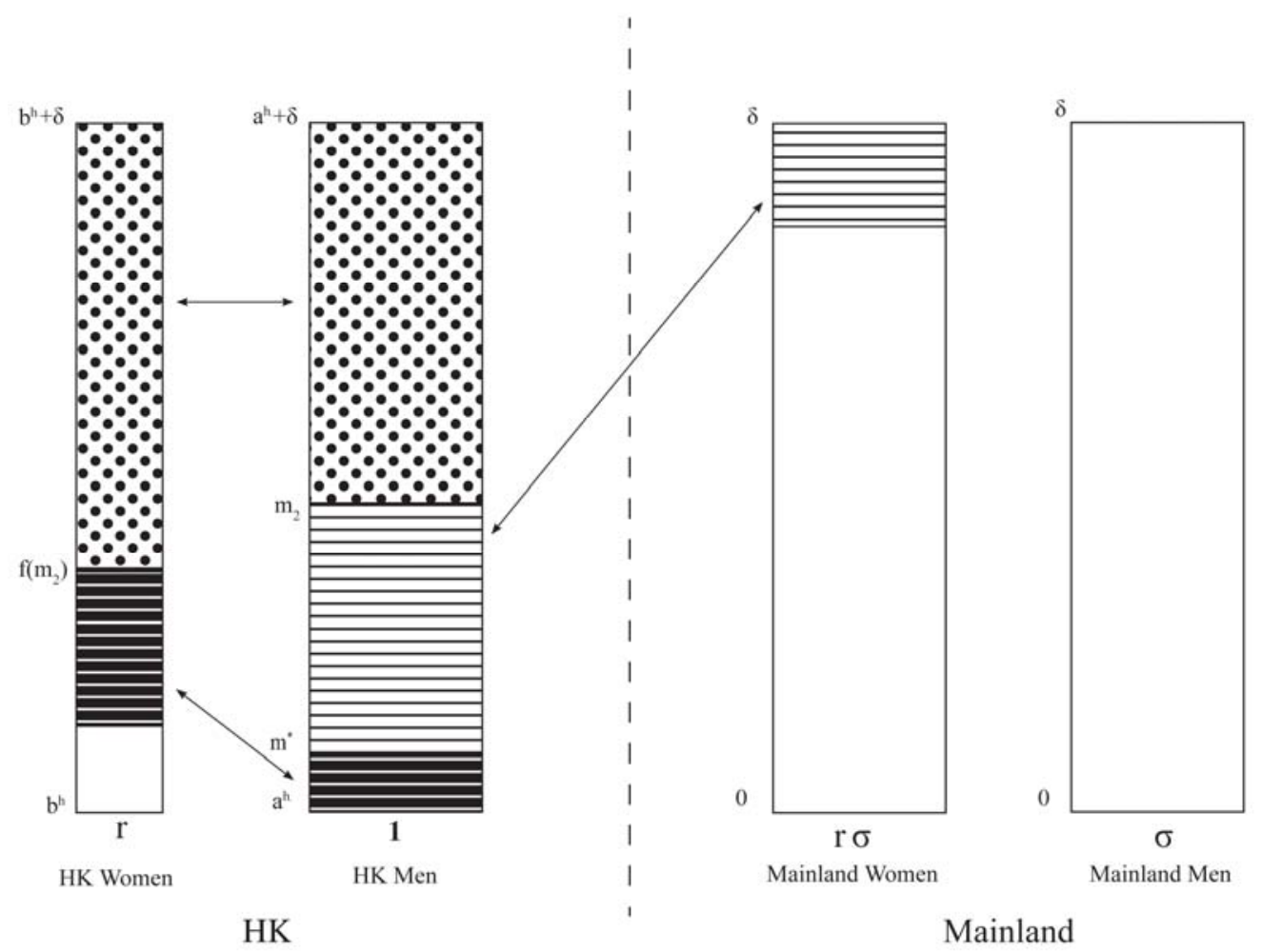

Figure 7. The assignment profiles in the corner solution with cross-boundary marriages 
Table 1a. Median age at marriage by residence of spouses, 2006

\begin{tabular}{|c|c|c|c|c|c|}
\hline & \multicolumn{5}{|c|}{ Marriage types by residence of spouses } \\
\hline & HK bride & $\begin{array}{l}\text { Mainland } \\
\text { bride }\end{array}$ & HK bride & Mainland bride & Total \\
\hline & $\begin{array}{l}\text { HK groom } \\
\text { (1) }\end{array}$ & $\begin{array}{l}\text { HK groom } \\
\text { (2) }\end{array}$ & $\begin{array}{l}\text { Mainland groom } \\
\text { (3) }\end{array}$ & $\begin{array}{l}\text { Mainland } \\
\text { groom } \\
\text { (4) }\end{array}$ & (5) \\
\hline Groom & 32.0 & 38.7 & 26.9 & 28.4 & 33.1 \\
\hline Bride & 29.5 & 28.8 & 27.2 & 26.0 & 29.4 \\
\hline
\end{tabular}

Note: The statistics only include all marriages registered in Hong Kong in 2006. 
Table 1b. Distribution of education attainments by residence of spouses, 2006

\begin{tabular}{|c|c|c|c|c|c|c|}
\hline \multirow[b]{2}{*}{$\begin{array}{l}\text { Education } \\
\text { attainment }\end{array}$} & \multirow[b]{2}{*}{ Sex } & \multicolumn{5}{|c|}{ Residence of spouses } \\
\hline & & $\begin{array}{l}\text { HK } \\
\text { bride } \\
\text { HK } \\
\text { groom }\end{array}$ & $\begin{array}{l}\text { Mainland } \\
\text { bride } \\
\text { HK groom }\end{array}$ & $\begin{array}{l}\text { HK bride } \\
\text { Mainland } \\
\text { groom }\end{array}$ & $\begin{array}{l}\text { Mainland } \\
\text { bride } \\
\text { Mainland } \\
\text { groom }\end{array}$ & Total \\
\hline $\begin{array}{l}\text { Primary or } \\
\text { below }\end{array}$ & $\begin{array}{l}\text { Groom } \\
\text { Bride }\end{array}$ & $\begin{array}{l}5.6 \% \\
6.9 \%\end{array}$ & $\begin{array}{l}25.8 \% \\
38.6 \%\end{array}$ & $\begin{array}{l}36.0 \% \\
28.0 \%\end{array}$ & $\begin{array}{l}32.7 \% \\
34.1 \%\end{array}$ & $\begin{array}{l}15.8 \% \\
20.8 \%\end{array}$ \\
\hline Secondary & $\begin{array}{l}\text { Groom } \\
\text { Bride }\end{array}$ & $\begin{array}{l}76.0 \% \\
78.8 \%\end{array}$ & $\begin{array}{l}71.9 \% \\
60.6 \%\end{array}$ & $\begin{array}{l}61.7 \% \\
70.6 \%\end{array}$ & $\begin{array}{l}63.5 \% \\
62.6 \%\end{array}$ & $\begin{array}{l}73.3 \% \\
71.1 \%\end{array}$ \\
\hline $\begin{array}{l}\text { Tertiary } \\
\text { (non-degree) }\end{array}$ & $\begin{array}{l}\text { Groom } \\
\text { Bride }\end{array}$ & $\begin{array}{l}11.8 \% \\
9.3 \%\end{array}$ & $\begin{array}{l}1.5 \% \\
0.5 \%\end{array}$ & $\begin{array}{l}1.4 \% \\
0.9 \%\end{array}$ & $\begin{array}{l}2.0 \% \\
1.9 \%\end{array}$ & $\begin{array}{l}7.0 \% \\
5.3 \%\end{array}$ \\
\hline $\begin{array}{l}\text { Tertiary } \\
\text { (degree) }\end{array}$ & $\begin{array}{l}\text { Groom } \\
\text { Bride }\end{array}$ & $\begin{array}{l}6.6 \% \\
5.0 \%\end{array}$ & $\begin{array}{l}0.8 \% \\
0.3 \%\end{array}$ & $\begin{array}{l}0.9 \% \\
0.6 \%\end{array}$ & $\begin{array}{l}1.7 \% \\
1.4 \%\end{array}$ & $\begin{array}{l}3.9 \% \\
2.8 \%\end{array}$ \\
\hline
\end{tabular}

Data source: Bacon-Shone, John, Joanna K.C. Lam, and Paul S.F. Yip, 2008, The Past and Future of the One Way Permit Scheme in the Context of a Population Policy for Hong Kong, Bauhinia Foundation Research Centre.

Note: The statistics only include all marriages registered in Hong Kong in 2006. 
Table 2a. Descriptive statistics of women (Hong Kong Censuses)

\begin{tabular}{|c|c|c|c|c|}
\hline & \multicolumn{4}{|c|}{ Censuses } \\
\hline & 1991 & 1996 & 2001 & 2006 \\
\hline \multicolumn{5}{|l|}{ Marital status } \\
\hline \multirow[t]{2}{*}{ Currently married } & 0.565 & 0.574 & 0.537 & 0.510 \\
\hline & {$[0.496]$} & {$[0.495]$} & [0.499] & {$[0.500]$} \\
\hline \multirow[t]{2}{*}{ Ever-married } & 0.586 & 0.608 & 0.586 & 0.572 \\
\hline & {$[0.493]$} & {$[0.488]$} & {$[0.492]$} & {$[0.495]$} \\
\hline \multirow[t]{2}{*}{ Currently divorced } & 0.013 & 0.024 & 0.038 & 0.051 \\
\hline & {$[0.111]$} & {$[0.152]$} & {$[0.191]$} & {$[0.220]$} \\
\hline \multicolumn{5}{|l|}{ Intrahousehold bargaining } \\
\hline Household head & $\begin{array}{c}0.133 \\
{[0.340]}\end{array}$ & $\begin{array}{c}0.159 \\
{[0.365]}\end{array}$ & $\begin{array}{c}0.193 \\
{[0.395]}\end{array}$ & \\
\hline \multicolumn{5}{|l|}{ Labor market } \\
\hline Labor force participation & $\begin{array}{c}0.652 \\
{[0.476]}\end{array}$ & $\begin{array}{c}0.664 \\
{[0.473]}\end{array}$ & $\begin{array}{c}0.702 \\
{[0.457]}\end{array}$ & $\begin{array}{c}0.722 \\
{[0.448]}\end{array}$ \\
\hline Employed & $\begin{array}{c}0.967 \\
{[0.178]}\end{array}$ & $\begin{array}{c}0.973 \\
{[0.163]}\end{array}$ & $\begin{array}{c}0.970 \\
{[0.172]}\end{array}$ & $\begin{array}{c}0.959 \\
{[0.199]}\end{array}$ \\
\hline Wage income & 7.300 & 14.027 & 16.884 & 16.658 \\
\hline (HK \$1,000) & {$[6.635]$} & [13.409] & [15.111] & [15.278] \\
\hline Hold a second job & $\begin{array}{c}0.020 \\
{[0.140]}\end{array}$ & $\begin{array}{c}0.016 \\
{[0.126]}\end{array}$ & $\begin{array}{c}0.021 \\
{[0.145]}\end{array}$ & $\begin{array}{c}0.019 \\
{[0.138]}\end{array}$ \\
\hline \multicolumn{5}{|l|}{ Other variables } \\
\hline Age & $\begin{array}{l}30.798 \\
{[8.317]}\end{array}$ & $\begin{array}{l}32.978 \\
{[8.795]}\end{array}$ & $\begin{array}{l}34.863 \\
{[9.868]}\end{array}$ & $\begin{array}{c}36.542 \\
{[10.502]}\end{array}$ \\
\hline Schooling years & $\begin{array}{c}9.507 \\
{[3.751]}\end{array}$ & $\begin{array}{l}10.504 \\
{[3.938]}\end{array}$ & $\begin{array}{l}10.817 \\
{[3.816]}\end{array}$ & $\begin{array}{l}11.591 \\
{[3.928]}\end{array}$ \\
\hline $\mathrm{N}$ & 45,903 & 55,876 & 63,515 & 67,972 \\
\hline
\end{tabular}

Data sources: Hong Kong censuses 1991, 2001, and by-censuses 1996, 2006

Note: Standard errors are in brackets. 
Table 2b. Descriptive statistics of men (Hong Kong Censuses)

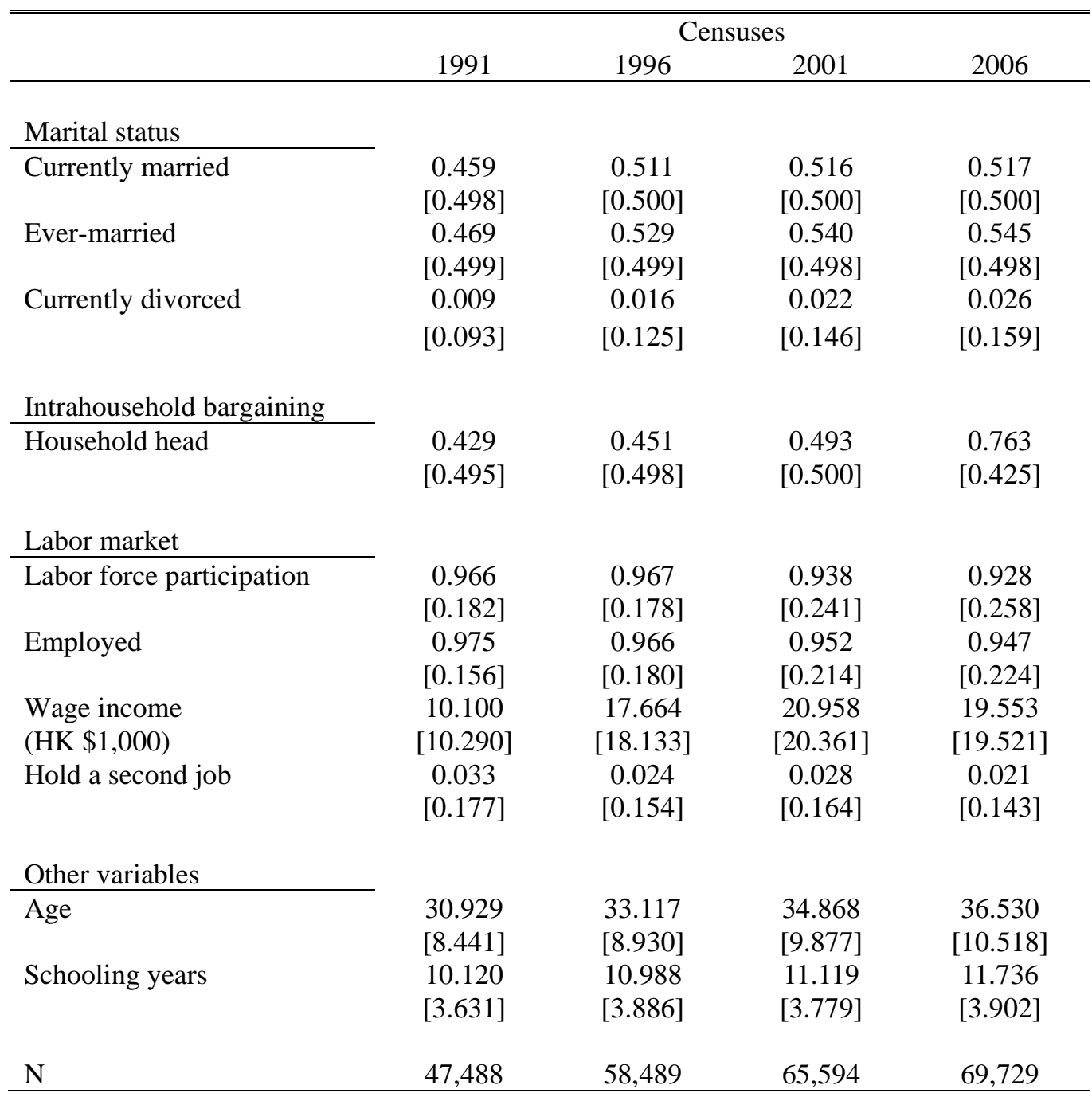

Data sources: Hong Kong censuses 1991, 2001, and by-censuses 1996, 2006

Note: Standard errors are in brackets. 
Table 2c. Descriptive statistics (Taiwan Censuses)

\begin{tabular}{|c|c|c|c|c|}
\hline & \multicolumn{2}{|c|}{ Census 1990} & \multicolumn{2}{|c|}{ Census 2000} \\
\hline & Women & Men & Women & Men \\
\hline \multicolumn{5}{|l|}{ Marital status } \\
\hline Currently married & $\begin{array}{c}0.687 \\
{[0.464]}\end{array}$ & $\begin{array}{c}0.635 \\
{[0.481]}\end{array}$ & $\begin{array}{c}0.628 \\
{[0.483]}\end{array}$ & $\begin{array}{c}0.593 \\
{[0.491]}\end{array}$ \\
\hline Ever married & $\begin{array}{c}0.729 \\
{[0.445]}\end{array}$ & $\begin{array}{c}0.658 \\
{[0.474]}\end{array}$ & $\begin{array}{c}0.684 \\
{[0.465]}\end{array}$ & $\begin{array}{c}0.627 \\
{[0.484]}\end{array}$ \\
\hline Currently divorced & $\begin{array}{c}0.022 \\
{[0.147]}\end{array}$ & $\begin{array}{c}0.019 \\
{[0.136]}\end{array}$ & $\begin{array}{c}0.037 \\
{[0.189]}\end{array}$ & $\begin{array}{c}0.031 \\
{[0.173]}\end{array}$ \\
\hline Intrahousehold bargaining & & & & \\
\hline Household head & $\begin{array}{c}0.136 \\
{[0.343]}\end{array}$ & $\begin{array}{c}0.636 \\
{[0.481]}\end{array}$ & $\begin{array}{c}0.244 \\
{[0.430]}\end{array}$ & $\begin{array}{c}0.599 \\
{[0.490]}\end{array}$ \\
\hline Other variables & & & & \\
\hline Age & $\begin{array}{l}33.379 \\
{[9.719]}\end{array}$ & $\begin{array}{l}33.928 \\
{[9.621]}\end{array}$ & $\begin{array}{c}35.329 \\
{[10.237]}\end{array}$ & $\begin{array}{c}35.622 \\
{[10.163]}\end{array}$ \\
\hline Schooling years & $\begin{array}{c}9.384 \\
{[4.035]}\end{array}$ & $\begin{array}{l}10.281 \\
{[3.618]}\end{array}$ & $\begin{array}{l}11.293 \\
{[3.405]}\end{array}$ & $\begin{array}{l}11.700 \\
{[3.141]}\end{array}$ \\
\hline $\mathrm{N}$ & 718,187 & 697,651 & $1,021,086$ & 984,698 \\
\hline
\end{tabular}

Data sources: Taiwan censuses 1990, 2000

Note: Standard errors are in brackets. 
Table 3. Cross-boundary marriages and family behaviors of Hong Kong residents, using Taiwan residents as a comparison group

\begin{tabular}{lccc}
\hline \hline & $\begin{array}{c}\text { Mean } \\
(1)\end{array}$ & $\begin{array}{c}\text { Women } \\
(2)\end{array}$ & $\begin{array}{c}\text { Men } \\
(3)\end{array}$ \\
\hline & \multicolumn{3}{c}{ Marital status } \\
\cline { 2 - 4 } & & $0.022^{* *}$ & \\
Currently married & 0.625 & {$[0.003]$} & $0.029^{* * *}$ \\
& & $-0.018^{* *}$ & {$[0.000]$} \\
Ever married & 0.336 & {$[0.003]$} & $0.027^{* * *}$ \\
& & $0.007^{* *}$ & {$[0.000]$} \\
Currently divorced & 0.028 & {$[0.001]$} & $-0.002^{*}$ \\
& & & {$[0.001]$} \\
& & Intrahousehold bargaining & \\
& & & $0.041^{* * *}$ \\
& & & {$\left[0.063^{* * *}\right.$} \\
Household head & 0.398 & $0.004]$ & \\
& & &
\end{tabular}

Data sources: Hong Kong censuses 1991 and 2001; Taiwan censuses 1990 and 2000.

Note: Column (1) shows the means of the dependent variables. We report the difference-in-difference estimates. Each entry in columns (2)-(3) comes from a separate regression of Equation (15) with the dependent variable listed in the left column. We report the difference-in-difference estimates. Age, age squared, educational years are included in all specifications. Robust standard errors adjusted for Hong Kong*census year clustering are reported in parenthesis. * Significant at $10 \%$; ${ }^{* *}$ significant at $5 \%$; *** significant at $1 \%$. 
Table 4. Cross-boundary marriages and the gender differences in family behavior of Hong Kong residents

\begin{tabular}{|c|c|c|c|c|}
\hline & $\begin{array}{c}\text { Mean } \\
(1) \\
\end{array}$ & $\begin{array}{c}\text { The whole } \\
\text { sample } \\
(2)\end{array}$ & $\begin{array}{c}\text { Highly } \\
\text { educated } \\
(3) \\
\end{array}$ & $\begin{array}{c}\text { Lowly } \\
\text { educated } \\
(4) \\
\end{array}$ \\
\hline & \multicolumn{4}{|c|}{ Marital status } \\
\hline Currently married & 0.523 & $\begin{array}{c}-0.077 * * * \\
{[0.022]}\end{array}$ & $\begin{array}{c}-0.029 \\
{[0.030]}\end{array}$ & $\begin{array}{c}-0.076^{* * *} \\
{[0.020]}\end{array}$ \\
\hline Ever married & 0.444 & $\begin{array}{c}-0.060 * * * \\
{[0.022]}\end{array}$ & $\begin{array}{c}-0.022 \\
{[0.030]}\end{array}$ & $\begin{array}{c}-0.056 * * * \\
{[0.020]}\end{array}$ \\
\hline \multirow[t]{2}{*}{ Currently divorced } & 0.026 & $\begin{array}{c}0.015^{* * *} \\
{[0.002]}\end{array}$ & $\begin{array}{c}0.007 * * * \\
{[0.002]}\end{array}$ & $\begin{array}{c}0.017^{* * *} \\
{[0.002]}\end{array}$ \\
\hline & \multicolumn{4}{|c|}{ Intrahousehold bargaining } \\
\hline \multirow[t]{2}{*}{ Household head } & 0.437 & $\begin{array}{c}-0.101 * * * \\
{[0.022]}\end{array}$ & $\begin{array}{c}-0.147^{* * *} \\
{[0.029]}\end{array}$ & $\begin{array}{c}-0.088 * * * \\
{[0.022]}\end{array}$ \\
\hline & \multicolumn{4}{|c|}{ Labor market } \\
\hline Labor force participation & 0.821 & $\begin{array}{c}0.081^{* * *} \\
{[0.017]}\end{array}$ & $\begin{array}{c}0.017 \\
{[0.011]}\end{array}$ & $\begin{array}{c}0.065^{* * *} \\
{[0.017]}\end{array}$ \\
\hline Employed & 0.962 & $\begin{array}{c}0.013 * * * \\
{[0.002]}\end{array}$ & $\begin{array}{l}0.006 * * \\
{[0.002]}\end{array}$ & $\begin{array}{c}0.016^{* * *} \\
{[0.002]}\end{array}$ \\
\hline $\ln$ (wage income) & 9.393 & $\begin{array}{c}0.005^{* * *} \\
{[0.017]}\end{array}$ & $\begin{array}{c}-0.007 \\
{[0.016]}\end{array}$ & $\begin{array}{c}0.004 * * \\
{[0.016]}\end{array}$ \\
\hline Hold a second job & 0.023 & $\begin{array}{c}0.006^{* * *} * \\
{[0.001]}\end{array}$ & $\begin{array}{l}0.004^{*} \\
{[0.002]}\end{array}$ & $\begin{array}{c}0.007 * * * \\
{[0.001]} \\
\end{array}$ \\
\hline
\end{tabular}

Data sources: Hong Kong censuses 1991 and 2001, and by-censuses 1996 and 2006.

Note: Column (1) shows the means of the dependent variables. Each entry in columns (2)-(4) comes from a separate regression of Equation (16) with the dependent variable listed in the left column. We report the difference-in-difference estimates. Age, age squared, educational years, and a time trend are included in all specifications. Robust standard errors adjusted for census year*female clustering are reported in parenthesis. * Significant at $10 \%$; ** significant at $5 \% ; * * *$ significant at $1 \%$. 
Table 5. Cross-boundary marriages and the emigration of Hong Kong residents to Canada and US

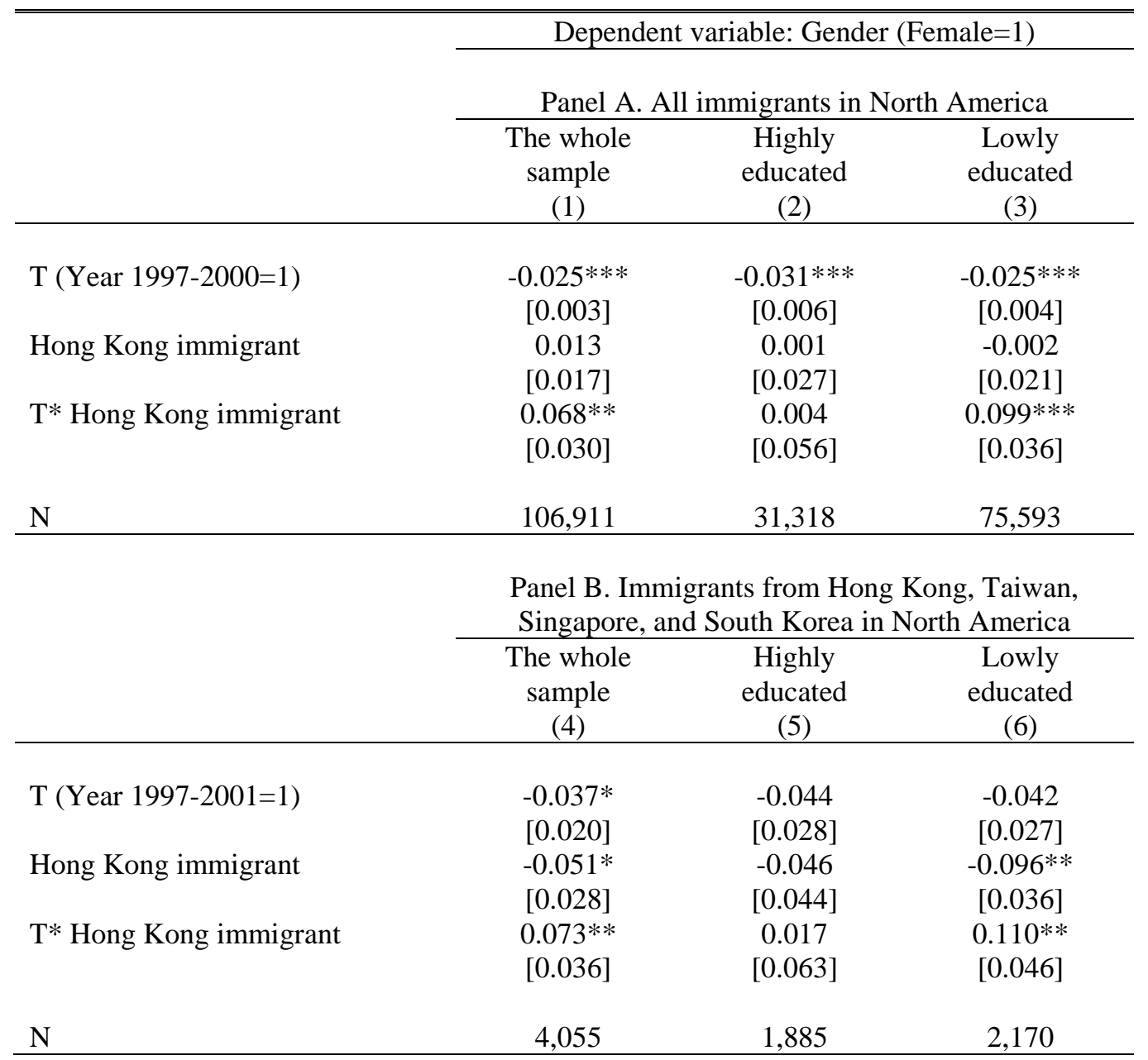

Data source: Canada population census 2001 and US population census 2000.

Note: Robust standard errors adjusted for census year*Hong Kong clustering are reported in brackets. * Significant at $10 \%$; $*$ significant at $5 \%$; ** significant at $1 \%$. Age, age squared, and a dummy of US census is included in all specifications. 